San Jose State University

SJSU ScholarWorks

Master's Theses

Master's Theses and Graduate Research

Spring 2012

\title{
Producing short and long run projections for the Ecological Footprint
}

David Gordon Moore

San Jose State University

Follow this and additional works at: https://scholarworks.sjsu.edu/etd_theses

\section{Recommended Citation}

Moore, David Gordon, "Producing short and long run projections for the Ecological Footprint" (2012).

Master's Theses. 4151.

DOI: https://doi.org/10.31979/etd.yuka-e9mh

https://scholarworks.sjsu.edu/etd_theses/4151

This Thesis is brought to you for free and open access by the Master's Theses and Graduate Research at SJSU ScholarWorks. It has been accepted for inclusion in Master's Theses by an authorized administrator of SJSU ScholarWorks. For more information, please contact scholarworks@sjsu.edu. 


\title{
PRODUCING SHORT AND LONG RUN PROJECTIONS FOR THE ECOLOGICAL FOOTPRINT
}

\author{
A Thesis \\ Presented to \\ The Faculty of the Department of Environmental Studies \\ San José State University \\ In Partial Fulfillment \\ of the Requirements for the Degree \\ Master of Science \\ by \\ David Gordon Moore
}

May 2012 
(C) 2012

David Gordon Moore

ALL RIGHTS RESERVED 
The Designated Thesis Committee Approves the Thesis Titled PRODUCING SHORT AND LONG RUN PROJECTIONS FOR THE ECOLOGICAL FOOTPRINT

by

David Gordon Moore

APPROVED FOR THE DEPARTMENT OF ENVIRONMENTAL STUDIES

SAN JOSÉ STATE UNIVERSITY

May 2012

Dr. William Russell

Department of Environmental Studies

Dr. Tom Means

Department of Economics

Dr. Douglas Greer

Department of Economics (emeritus) 


\section{ABSTRACT \\ PRODUCING SHORT AND LONG RUN PROJECTIONS FOR THE ECOLOGICAL FOOTPRINT \\ by David Gordon Moore}

The Ecological Footprint is a useful tool for public awareness of ecological pressures and for policymakers who aim to reduce them. In order to determine the potential effects of future actions and policies, it is necessary to construct scenarios of future global conditions, both in the short-term and long-term. This study develops two alternative methods for creating Ecological Footprint scenarios: first using asymmetric changes in simple economic output (GDP) to look at short-term projections; then using widely accepted scenarios from international agencies to develop long-term projections.

Changes in GDP were found to be causal in determining changes in the Ecological Footprint, and this method can be used for "nowcasting" and projecting the future Ecological Footprint. Furthermore, it was found that the projections from different agencies can be combined under a single Ecological Footprint framework, but there are certain inconsistencies across projections that are highlighted. Lastly, the use of dynamic Ecological Footprint models based on computable general equilibrium models is explored as the preferred solution for the creation of policy-relevant tools. 


\section{ACKNOWLEDGEMENTS}

This thesis has depended on the support of many, with the obvious inclusion of my committee, and to each of them I extend my thanks.

Without the generous donation of extensive Ecological Footprint accounts by the staff at the Global Footprint Network, this work would not have been possible. I would especially like to thank Brad Ewing and Mathis Wackernagel for their provision of this data.

The developers of the free, open source GRETL econometrics library have made data analysis easy and fun, and to them I give thanks and my admiration. More information regarding the software can be found at http://gretl.sourceforge.net/.

Finally, I would like to thank my wife who has given support, criticism, and a helpful ear throughout this project, despite being overwhelmed with her own work and the new addition to our family. 


\section{TABLE OF CONTENTS}

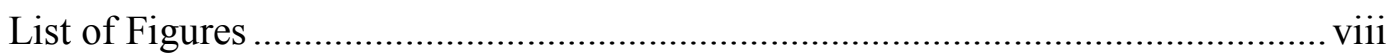

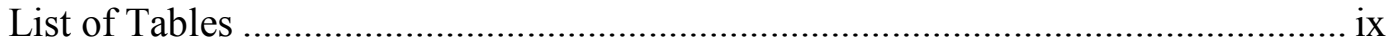

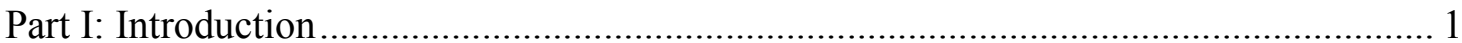

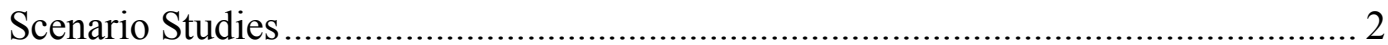

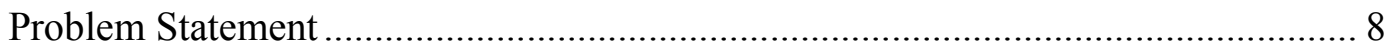

Part II: Short-term Ecological Footprint Projections using the Asymmetric Effects of

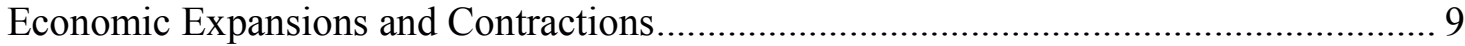

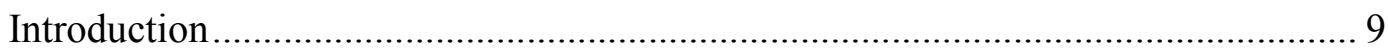

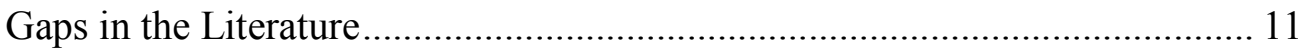

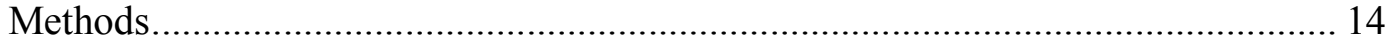

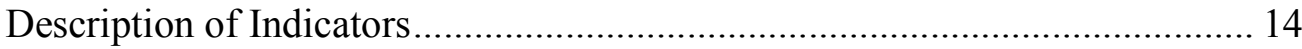

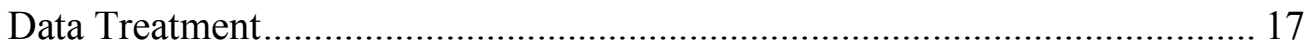

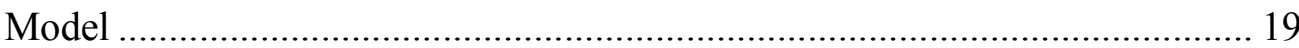

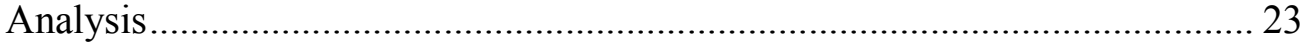

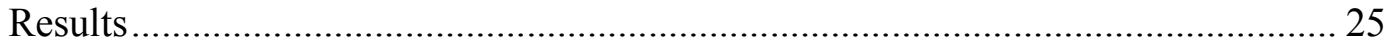

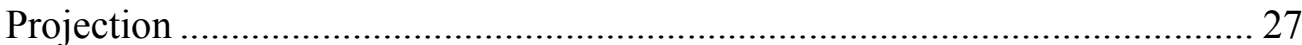

Part III: Long-term Ecological Footprint Projections using Estimates from

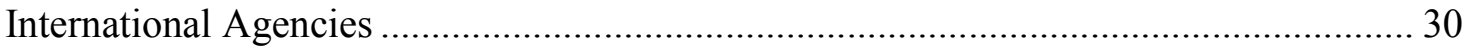

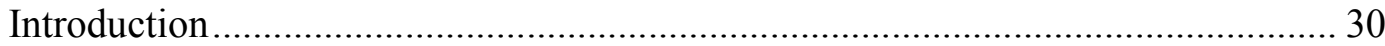

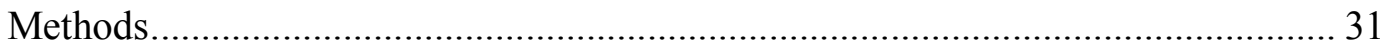

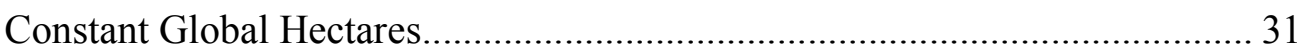

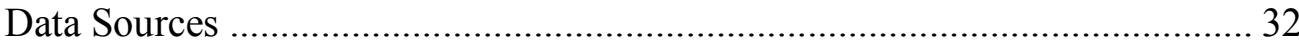

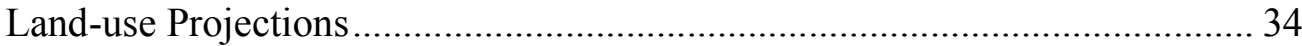

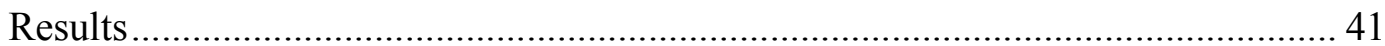

Part IV: Evaluation of methods for ecological footprint projections............................ 47

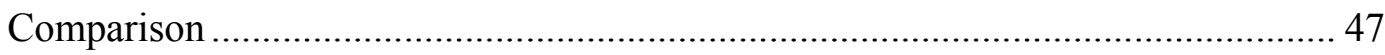

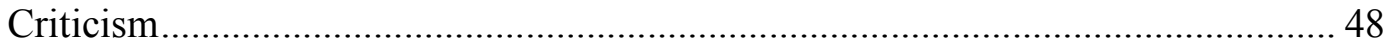




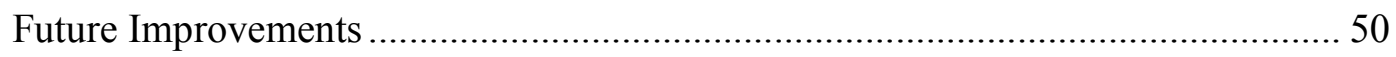

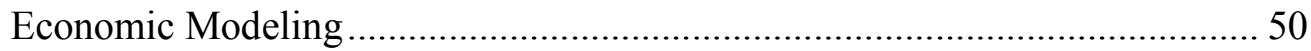

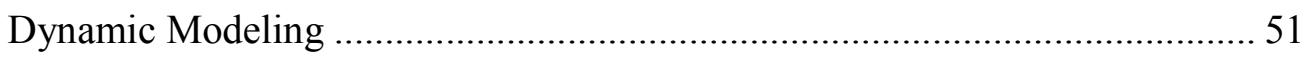

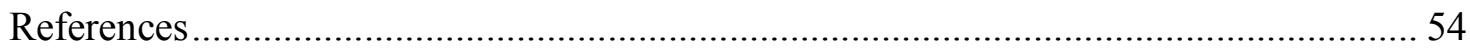

Appendix A - Stata code for variable creation .................................................................. 59

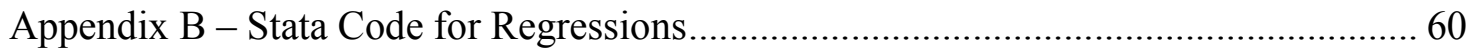

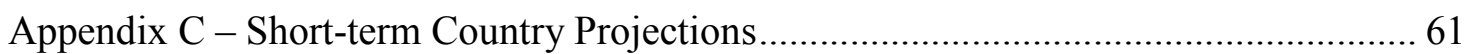




\section{LIST OF FIGURES}

Figure 1. The decomposition of Japan's total GDP from 1990-2010.

Figure 2. Historical and projected global total Ecological Footprint, projected using asymmetric effects of changes in economic output.

Figure 3. Historical and projected global Ecological Footprint per capita, projected using asymmetric effects of changes in economic output.

Figure 4. Historical and projected global Ecological Footprint using long-term baseline scenario projections.

Figure 5. Historical and projected global biocapacity using long-term baseline scenario projections.

Figure 6. Comparison of the Ecological Footprint to biocapacity ratio for BLUE map and baseline scenarios.

Figure 7. Comparison of the impact of dietary patterns on the Ecological Footprint. .... 45

Figure 8. The Ecological Footprint to biocapacity ratio for the most aggressive Footprint reduction scenario 46 


\section{LIST OF TABLES}

Table 1. Summary of selected important EKC literature, illustrating the gaps or shortcomings in current knowledge.

Table 2. Fixed effects estimation of impact on the Ecological Footprint of production by changes in GDP, with significance of asymmetric impacts

Table 3. 2-stage Least Squares estimation, using 5-year lagged GDP increase as an instrument for GDP increase.

Table 4. 2-stage Least Squares estimation, using 5-year lagged GDP decrease as an instrument for GDP decrease.

Table 5. The percentage composition of the Ecological Footprint in 2008 and (projected) in 2016

Table 6. Summary of exogenous variables used in the long-term scenario projections... 


\section{PART I: INTRODUCTION}

In realms outside physical processes, the future is uncertain; it is difficult to know what challenges, developments, and changes lie ahead. However, decisions are made every day that will have significant effects on the future sustainability of humanity (DeFries, Foley and Asner 2004). Consequently, world leaders need tools that enable them to make decisions in the midst of so many unknowns; scenario formulation is one such tool (Ringland 2002). Scenarios are regularly used in relation to, for example, climate change and sustainable development in order to highlight different pathways into the future following a variety of energy-use strategies, population growth, and economic development (DeFries, Bounoua and Collatz 2002, Arnell 2004).

It is very hard to imagine what the future may be like in a hundred years time. The world has changed considerably in the last century (DeFries, Foley and Asner 2004, Ellis, et al. 2010, Foley, et al. 2005, Rockström, et al. 2009, Ramankutty and Foley 1999, Ramankutty, Foley and Olejniczak 2002), with the development of aviation, space exploration, computer information technology, and the world Wide Web. Many of these things would have appeared completely alien and abstract at the start of the 20th century. This makes it very difficult to estimate what advances may occur in technology and how the world's demographic and energy-use, for example, may have altered by the end of the 21st century (Popp, Newell and Jaffe 2009). As well as technological changes, there will likely be a shift in geo-political powers, and alterations in societal beliefs and behaviors (Barkmann, et al. 2008). Scenarios are vital to an ongoing global assessment of sustainability. They allow for an engagement with different future developments in 
systems that are complex, inherently unpredictable, and have many associated uncertainties (Postma and Liebl 2005). They can be used to illustrate a variety of possible changes resulting from different demographic patterns, economic developments, and environmental concerns. This enables policy and decision makers to be better informed and have a good basis on which to assess strategies for adaptation, mitigation, and prevention mechanisms.

Scenarios are not predictions or forecasts; they simply tell a coherent story of potential future pathways. They are not intended to illustrate preferable developments or undesirable progressions, but instead describe a host of plausible futures and further understanding about how systems evolve, develop, behave, and interact. Policy makers can use scenarios to better appreciate the effects of climate change or resource constraints and gain insight into different adaption, mitigation, and impacts that may occur.

\section{SCENARIO STUDIES}

There is a vast body of literature regarding scenario formulation covering narrative descriptions, quantitative scenarios, and detailed models (Cranston and Hammond 2010). Scenarios are frequently used in the private sector and by bodies such as the Inter-governmental Panel on Climate Change (IPCC), where the focus has been on greenhouse gas (GHG) emissions (Nakicenovic, et al. 2000). This enables the study of future energy and related industrial developments, and the way in which the resulting GHG emissions may impact climate change over a given period. Considerable uncertainty surrounds climate change, particularly the interaction and long-term impacts 
of anthropogenic emissions within the atmosphere. Scenarios looking at changes in landuse have also been explored, especially within the developed world (Rounsevell, et al. 2006) in order to explore future constraints on land-use planning. However, these studies often rest on large assumptions, and the incorporation of models and statistical techniques add layers of complexity that can obscure their utility. The task of anticipating future developments is difficult especially when considering an extremely long time period. Nevertheless, long-term scenarios have been developed for the "visioning" of global energy trends and strategies in the context of climate change science (Schmidhuber and Tubiello 2007). These facilitate an analysis of the way in which future global developments will influence the concentration of GHGs in the atmosphere, and their possible impact on climate change. Scenarios of the latter type fall into two categories: those that consider the uncertainties in the drivers for emissions (such as population, economic wealth, and technology), or those that analyze uncertainty in the levels of commitment and effectiveness of global efforts to reduce climate change. The first global sustainability study using scenarios was undertaken by the International Institute for Applied Systems Analysis (IIASA), detailed in their book Energy in a Finite world (Hafele 1981). The world was understood to be dynamic, with a growing population, changing economies, and aspirations to achieve suitable development and growth to realize reasonable living standards. The focus was upon energy-use and the required energy levels necessary to accomplish development, particularly within the southern hemisphere. In a similar fashion to the IPCC (Nakicenovic, et al. 2000), the IIASA assumptions excluded political constraints and were limited to more realistic scenarios 
with no "surprises" or catastrophes included within the data sets. A 50 year timescale was chosen based upon twice the lifetime of power plants, lead times for new technologies, and two generations of humanity, therefore encompassing major changes while being within the limitations of realistic projections.

Since the recent rise in interest concerning climate change and a consciousness of humanity's impacts on the Earth, many more scenarios have been explored, not just by academic institutions, but also by businesses and governments. The world Business Council for Sustainable Development has investigated scenarios within their Vision 2050 project (WBCSD 2010). This details a pathway leading to a sustainable world in 2050, through changes in economic structures, governance, business, and fundamental human behavior, and with the goal of humanity living well within the planet's capacity. As such scenarios can be used to advise and steer decision makers, governments and world leaders towards understanding the consequences of their policies and decisions to give the best outcomes for humanity as well as the world. The World Energy Council also assesses scenarios for carbon emissions and energy-use. Most recently, the report Energy Policy Scenarios to 2050 (WEC 2007) builds upon earlier work (WEC 1993) and utilizes recent updates to account for new estimates regarding population, technological development, and climate change. These scenarios tend to be based upon the engagement of governments across different regions of the world, the different energy sector changes and the subsequent challenges that arise. The Global Footprint Network has also undertaken scenario analysis making suggestions as to future ecological debt, following a business-as-usual trend, slow shift scenario, and rapid reduction assumptions 
(WWF 2006) as well as a possible "return to sustainability" pathway (WWF 2008). The IPCC has been developing scenarios since 1990, their IS92 report offered emission scenario projections up to 2100 (Nakicenovic, et al. 2000). They were considered to be path breaking since they included a host of GHG and SO2 emissions. However, a number of weaknesses were identified, such as the limited range of carbon dioxide intensities and the continuation of the income gap between developing and developed countries with no convergence into the future. The scenarios were updated following this critique with a better understanding of climate change and its appropriate determinants, resulting in the Special Report on Emissions Scenarios (SRES) (Nakicenovic, et al. 2000). These scenarios have been readily adopted within academic circles and businesses alike due to the diversity of projections, the level of detail and scrutiny the report has undergone, and the international recognition of the IPCC as a world leading group with the capacity and capability to develop scientifically acceptable arguments.

The Ecological Footprint measures the number of biotic resources needed to meet humanity's demand for raw materials and sequestration of carbon dioxide emissions (Galli, et al. In Press, Wackernagel, Lewan and Hansson 1999, Wackernagel, Onisto, et al. 1999, Wackernagel, Schulz, et al. 2002). The strength of the measure lies in both its comprehensive coverage of human demands on renewable resources and in its ability to be compared to biocapacity: the ability of the Earth to meet these needs. Scenario analyses of future trends in the Ecological Footprint have the potential to inform today's policies aimed at creating a sustainable future. A number of such scenarios have been performed, with varying levels of sophistication in the analysis (Ferng 2009, Lenzen, et 
al. 2007, van Vuuren and Bouwman 2005) and usually without the inclusion of rigorous biocapacity estimates. However, complex models such as these studies have a number of challenges (Pilkey and Pilkey-Jarvis 2007), including:

1. Insufficient data may lead to the use of inappropriate assumptions.

2. Embedded assumptions and inaccuracies may become compounded.

3. Increasing difficulty in error-checking or incorporation of new data.

There is, therefore, a need for a relatively simple, consistent scenario tool that avoids the use of extensive modeling and, by use of transparent model equations, simply translates accepted projections into Ecological Footprint and biocapacity terms. In some ways, this has been attempted in the past: many studies attempt to make a quantitative link between economic output (i.e. Gross Domestic Product) and the Ecological Footprint (Mattila 2012, Bagliani, Bravo and Dalmazzone 2008, Dietz, Rosa and York 2007). While useful, many of these have been couched in terms of the Environmental Kuznets Curve, which has problems of constraining the model to a quadratic form. Additionally, these studies have primarily looked at the Ecological Footprint of consumption (Bagliani, Bravo and Dalmazzone 2008), which bears less of a direct tie to domestic output than does the Ecological Footprint of production (since consumption can also be based on imports sustained through the acquisition of debt). Lastly, nearly all prior studies looking at such linkages ignore the potential for asymmetric responses resulting from output expansion and contraction, despite the very different pressures on a nation's industries that result (Ching, Ip and Chan 2009). 
This study thus attempts to correct for these prior deficiencies and establish a causal link between nations' economic output and their ecological resource use. The most difficult part of using such a model to make projections into the future is the unknown technological changes that will occur. This link will therefore only be used for making short-term projections of about 5 years after the final year of available Ecological Footprint data.

In order to make more long-term projections, this study will defer to expert analysis in each of the Ecological Footprint component areas. These analyses are widely published by organizations such as the Food and Agriculture Organization (FAO) and the International Energy Agency (IEA), and, in contrast to the short-term model described above, are much more focused on potential changes in consumption (rather than production). Incorporating these existing projections into the Ecological Footprint framework will allow relatively robust long-term projections without the need to defend the underlying assumptions. Additionally, this type of analysis will demonstrate potential areas of constraint and highlight potential mitigation strategies. The projections from international agencies are often focused on narrow spheres of interest and may be incompatible with each other. Since the Global Footprint Network's National Footprint Accounts (NFA) are structured to monitor the combined impact of anthropogenic pressures more typically evaluated independently (Galli et al., this issue), they already present a framework for combining historical datasets from diverse sources (Ewing et al., 2008). This framework can thus be extended to utilize future projections of these datasets. 


\section{PROBLEM STATEMENT}

The National Footprint Accounts released by the Global Footprint Network take advantage of the most recent, consistent data sets possible. However, following the current yearly release schedule, data are usually only available up to a minimum of three years before present (e.g. 2008 for the 2011 release of the National Footprint Accounts). This presents a problem for communication to the public, who usually want to see the effects of recent events on the Ecological Footprint.

Furthermore, the Global Footprint Network argue that the Ecological Footprint and biocapacity are going to become ever more important in determining economic pathways for countries (Moore and Galli 2010). Therefore, knowing the potential constraints arising from global supply and demand on ecological resources will assist policy makers in development of national strategic plans.

In the past, models developed to determine potential projections for the Ecological Footprint have suffered from oversimplification (e.g. exclusion of important explanatory variables), or over-complication (e.g. models based on assumptions which could be disputed). There is, therefore, a need for simple, comprehensible, and robust projections of the Ecological Footprint, both in the short-term for communications purposes and long-term for planning purposes. 


\section{PART II: SHORT-TERM ECOLOGICAL FOOTPRINT \\ PROJECTIONS USING THE ASYMMETRIC EFFECTS OF ECONOMIC EXPANSIONS AND CONTRACTIONS}

\section{INTRODUCTION}

A large quantity of national statistical resources is used in the development and maintenance of national economic accounts, particularly in the measurement of Gross Domestic Product (GDP), which represents the sum of the final value of all goods and services produced within a country's borders (Mäler 1991). Since so many policy decisions are based upon this measurement, there is much scrutiny paid to its accuracy and consistency; GDP is a high quality candidate for making short-term projections.

Sustainable growth has been defined as "meeting the needs of the present without compromising the ability of future generations to meet their needs." The literature on this has been well developed in the last twenty years, with the consensus leaning towards the interpretation of maximizing economic growth in the present and the future (Giddings, Hopwood and O'Brien 2002). A significant amount of this work has been focused on establishing links between economic growth and environmental consequences, and therefore aids the development of models for projections based on economic growth.

Much of the work towards the interpretation of sustainable growth has been the development of the concept of the Environmental Kuznets Curve (EKC), where once a 
certain level of income is achieved a decrease in a society's environmental impact with increasing income is hypothesized. The mechanism for this is posited to be that a certain level of income results in both environmental regulatory pressure and the technological capability to achieve it. A number of cross-country studies find evidence of this for some environmental variables (Selden and Song 1994, Grossman and Krueger 1995, Shafik and Bandyopadhyay 1992).

However, some critics of the standard EKC concept argue that there is likely to be an upper limit to achieving ever-greater efficiency in energy and material use. Therefore, despite the observed reduction in environmental impact for some variables, they may increase again with economic growth (de Bruyn and Opschoor 1997). Furthermore, the EKC has only been observed for variables whose effects are felt by the society that is local to the entities responsible for the environmental degradation. This would leave global environmental problems unresolved (de Bruyn, van den Bergh and Opschoor 1998).

At the scale of a national economy, however, there are hints that economic contraction is beneficial to the environment. It is noted that there are significant costs to economic growth in the short-term, which, combined with an uncertain outcome in the long-term, appeals to a policy of no-growth (de Bruyn, van den Bergh and Opschoor 1998). Observations of countries that experienced significant contractions, such as the NIS of the former Soviet Union, find that air and water pollution dropped extremely rapidly as industrial output collapsed (Cherp and Mnatsakanian 2003), and there are 
reports that recessions are beneficial in many health indicators. At least one of these, infant mortality, is directly related to the sharp decrease in air pollution at these times (Chay and Greenstone 2003, Ruhm 2006).

It is further noted that it is not only the absolute levels of environmental impact that fall at these times, which might be expected, but also the levels relative to output: an increase in efficiency. The recession in the early 1980s was associated with a low-point in materials and energy throughput relative to GDP (de Bruyn and Opschoor 1997). The early 1990s recession was associated with an increase in transport activity, but a decrease in transport energy-use (Murtishaw and Schipper 2001).

There is a corresponding amount of evidence that contracting economies can result in environmental problems. Specifically, the money available for environmental cleanup of degraded zones shrinks, and the energy to GDP ratio for the whole US economy declined at its lowest rate during the early 1990s recession (Cherp and Mnatsakanian 2003, Murtishaw and Schipper 2001).

\section{Gaps in the Literature}

Table 1 summarizes some of the most important pieces of EKC literature that have furthered the boundaries of knowledge beyond the simple establishment of an inverted U-curve. However, there are limitations to these studies (marked in grey), which are explored below. 
Table 1. Summary of selected important EKC literature, illustrating the gaps or shortcomings in current knowledge (grey).

\begin{tabular}{|l|l|l|l|l|l|}
\hline Author & $\begin{array}{l}\text { Impact } \\
\text { Variable }\end{array}$ & $\begin{array}{l}\text { Income } \\
\text { variable }\end{array}$ & $\begin{array}{l}\text { Income } \\
\text { direction }\end{array}$ & $\begin{array}{l}\text { Sample } \\
\text { Size }\end{array}$ & $\begin{array}{l}\text { Time } \\
\text { Range of } \\
\text { Data }\end{array}$ \\
\hline $\begin{array}{l}\text { (Vehmas, } \\
\text { Luukkanen and } \\
\text { Kaivo-oja 2007) }\end{array}$ & $\begin{array}{l}\text { Materials } \\
\text { flow (per } \\
\text { capita } \text { and } \\
\text { total) }\end{array}$ & $\begin{array}{l}\text { GDP } \\
\text { (Total) }\end{array}$ & $+/-$ & EU-15 & $1980-2000$ \\
\hline (Rothman 1998) & $\begin{array}{l}\text { EF (per } \\
\text { capita) }\end{array}$ & $\begin{array}{l}\text { GDP (per } \\
\text { capita) }\end{array}$ & + & 52 & 1992 \\
\hline $\begin{array}{l}\text { (Gately and } \\
\text { Huntington 2002) })\end{array}$ & $\begin{array}{l}\text { Energy-use } \\
\text { (per capita) }\end{array}$ & $\begin{array}{l}\text { GDP }(\text { per } \\
\text { capita) }\end{array}$ & $+/-$ & 96 & $1971-1997$ \\
\hline $\begin{array}{l}\text { (Bagliani, Bravo } \\
\text { and Dalmazzone } \\
\text { 2008) }\end{array}$ & $\begin{array}{l}\text { EF (per } \\
\text { capita })\end{array}$ & $\begin{array}{l}\text { GDP }(\text { per } \\
\text { capita })\end{array}$ & + & 141 & 2001 \\
\hline
\end{tabular}

\section{Impact Variable}

All the articles selected use some aggregated form of environmental impact, whether measuring the materials flow through the economy, the Ecological Footprint, or energy-use. Rothman makes his study using the Ecological Footprint in 1998, when the measure was still in its infancy. Since then, there have been numerous revisions and improvements. Gately's use of energy-use as his dependent variable is more comprehensive than many previous studies (there are few substitutes for energy), but is not as inclusive as the Ecological Footprint.

The use of aggregate measures represents an important step beyond the single environmental indicator estimations that continue to be used (which neglect the possibility of income increases merely shifting the type of destructive technology used). However, in an attempt to standardize across countries, three out of the four use impacts 
per capita as the dependent variable (Vehmas et al explore both per capita and total). However, sustainability (i.e. operating at an impact level below the carrying capacity) is dependent upon total environmental impacts, not per capita impacts.

\section{Income Direction}

As described above, most EKC literature to date has fixed the environmental impacts of income decreases as being the perfect reversal of income increases. This could be due to an oversight, model simplification, or simply because of the lack of data for countries that have experienced significant contractions. Of the four presented here, Vehmas and Gately both allow for asymmetric effects from income increases and decreases, while Rothman and Bagliani both follow the traditional, oversimplified model.

\section{Sample Size and Time Range}

Unfortunately, Vehmas limits his research to the EU-15 countries (likely based on availability of information for his selected dependent variable). As observed, none of these countries have experienced significant contractions in the time period examined, effectively eliminating the ability to derive significant information of the effects of income decreases on the environment. Rothman and Bagliani both limit their studies to cross-sections for a fixed year; a significant deficit as it is then extremely difficult to extrapolate this information to the likely path that will be followed by a single country. Gately uses panel data over a relatively wide time-period, garnering useful information, but is somewhat limited by his use of a relatively restricted dependent variable. 


\section{Summary}

The limitations imposed by sample size and time range effectively leaves only Gately as an appropriate model, which finds that energy-use responds less to income decreases than to increases. Therefore, it seems that there is a significant gap in the literature for a global, long-term study of system-wide environmental impacts that respond differently to economic expansions and contractions.

\section{METHODS}

\section{$\underline{\text { Description of Indicators }}$}

GDP

Despite ongoing criticism in academia, gross domestic product (GDP) remains a popular, available measure of welfare within a country. GDP measures the sum of all final goods and services produced within a country in a given year, and consequently it is also equal to the income received by a country within that year. Therefore, GDP per capita measures the average (mean) yearly income received by individuals.

Total GDP in constant 2000 \$US (and thereby limiting the effect of inflation) is available from the World Bank from 1960 to 2008 (World Bank 2011) and was used for this study. The intersection between this dataset and the Ecological Footprint dataset covers 173 countries over 47 time periods. 


\section{Ecological Footprint}

Traditional environment-economic analyses have made a number of simplifications that make them highly susceptible to missing the effects of income on environmental impact. The majority looks at only a single indicator of impact, such as emissions of sulfur dioxide. In this case, a shift to another, perhaps more damaging, pollutant will show up as evidence of an Environmental Kuznets Curve effect.

Additionally, by using environmental impact per capita as the dependent variable, the positive move towards sustainability that population growth restriction may have is discounted by many studies.

We seek in this study to explore the effect that changes in production have on the natural environment as a whole, an aggregate indicator is needed. Such an indicator that is becoming more widespread is the Ecological Footprint.

The Ecological Footprint represents the appropriated availability of bioproductive land, expressed as

$$
E F=\frac{P}{Y_{N}} \cdot Y F \cdot E Q F
$$

where

- $\quad P$ is the amount of a product harvested or the amount of waste emitted. For example, in the United States in 2008, 4.4 million tones of apples were produced.

- $Y_{N}$ is the average yield for $P$ in that country. For example, in the United States in 2008, the average apple yield was 30.8 tonnes per hectare; $\frac{P}{Y_{N}}$ thus gives the area used for the production of the product, $P$. 
- $\quad Y F$ is the yield factor for the type of land-use (cropland, pasture land, forest, built land, fishing grounds, and carbon uptake land) in question. The yield factor incorporates the differing levels of productivity between countries for each landuse type and is calculated as the ratio of national yield to world average yield. For example, a hectare of cropland in the United States was 1.07 times more productive than world average cropland in 2008. A full set of yield factors are available upon request from the Global Footprint Network.

- $E Q F$ is the equivalence factor for the land-use type. Equivalence factors allow the direct comparison of different land-use types. These equivalence factors are based on the suitability of the land to grow crops, as defined in the Global AgroEcological Zones (GAEZ) database developed by the Food and Agriculture Organization (FAO). Built land is assumed to have the same equivalence factor as cropland (as cities often grow into former cropland), and the equivalence factor for water (marine and freshwater) is set so that a global hectare of water dedicated to salmon farming produces the same number of calories as a global hectare of pasture dedicated to beef farming. In 2008, the equivalence factor for cropland was 2.51; meaning that cropland-occupied land that was, on average, 2.51 times more productive than the average piece of land providing resources for humans. A full time series of equivalence factors is available upon request from the Global Footprint Network. 
The Ecological Footprint is a very conservative measure of impact on the environment, focused entirely on renewable processes and ignoring all waste products that cannot be reabsorbed directly into the biosphere (notably plastics, spent nuclear material, and methane). Consequently, shifts to industries such as dairy farming and nuclear energy will appear to decrease the Ecological Footprint.

The dataset used in this study is the 2011 revision, provided by the Global Footprint Network. These data contain the Footprint for over 200 countries over a timeperiod from 1961-2008. A number of indicators are provided: this study uses the total Ecological Footprint of Production (EFProdTotGHA). All the articles selected use some aggregated form of environmental impact, whether measuring the materials flow through the economy, the Ecological Footprint, or energy-use. This represents an important step beyond the single environmental indicator estimations that continue to be used (which neglect the possibility of income increases merely shifting the type of destructive technology used).

\section{$\underline{\text { Data Treatment }}$}

\section{Asymmetry}

The majority of the literature on EKC has made the assumption that income increases and income decreases have an equal magnitude effect on environmental impact. This untested restriction has been commented on in other fields such as fertility models and remains common in empirical research (Haynes, 1983). 
In more closely related fields it has been shown that demand for goods responds asymmetrically to price and income increases and decreases (Gately and Huntington 2002, Mork 1989, Vehmas, Luukkanen and Kaivo-oja 2007). Gately decomposed oil price into three components: maximal increases (where the price reaches a new maximum), decreases, and sub-maximal increases. The additional complexity of breaking price increases into two (new maxima and sub-maximal increases) is useful for the volatile oil market, where a lot of attention is paid new price maxima. However, in income and development assessments, new income maxima are frequent occurrences. Consequently, a simplified model was used that simply disaggregates production changes into production increases and production decreases (see Figure 1).

$Y_{t}^{+}=\sum_{t=1}^{t} \Delta Y_{t} ;$ when $\Delta Y$ is $>0$

$Y_{t}^{-}=\sum_{t=1}^{t}-\Delta Y_{t} ;$ when $\Delta Y<0$

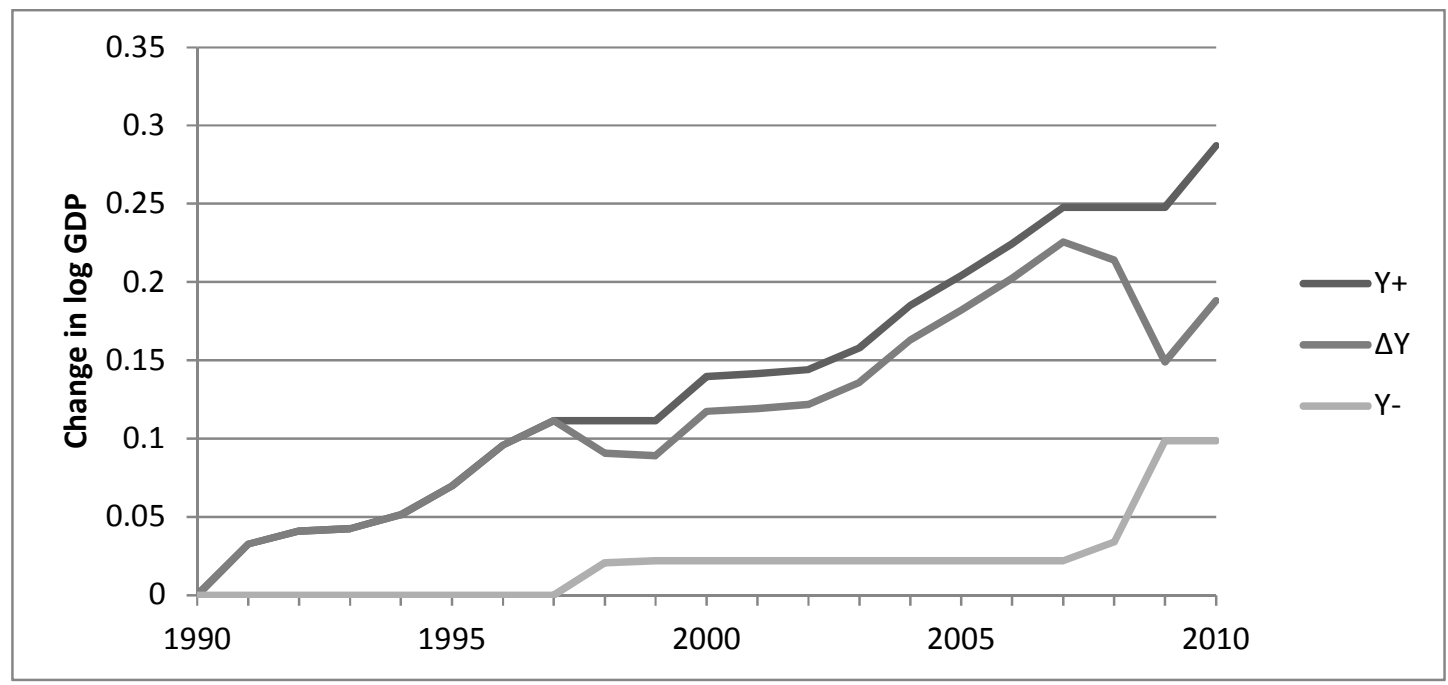

Figure 1. The decomposition of Japan's total GDP from 1990-2010 (World Bank 2011). The change in log total GDP is equal to $\mathrm{Y}^{+}$minus $\mathrm{Y}^{-}$. 


\section{Projections}

Once the relationship between changes in economic output and the Ecological Footprint of production has been established, this can be combined with measurements and projections of GDP to extend the estimate of countries' Ecological Footprints to the present (the Global Footprint Network estimates only extend to three years before present), and into the near future.

The preferred measurements and estimates used here are from the IMF's world Economic Outlook publication (IMF 2011). These present, for most countries around the world, GDP measurements and estimates up to 2016. The average change across all countries (weighted by total output) was used to estimate percentage changes in the global Ecological Footprint and produce a global projection.

\section{$\underline{\text { Model }}$}

\section{Fixed Effects Regression}

Previous studies that have looked at the relationship between economic output and environmental impact have often forced a quadratic relationship into the model, in order to evaluate the Environmental Kuznets Curve hypothesis. This study does not place such a restriction. Since it is expected that the size of an economy increase at a different rate to its Ecological Footprint (in essence we are comparing a volume to an area), a log-log specification is used. 
In addition to the decomposed economic variables, this study controls for population and time. The time variable is critical to include, and captures a hypothetical linear change in technological efficiency.

The panel data used here (combined cross-section and time series data) necessitate an allowance for unobserved variables that differ across countries in order to determine the effect over time of changes in economic output. Formally, this is included through running a fixed effects regression, which introduces a dummy variable for each cross sectional variable (i.e. country). The estimated model is therefore:

$E F_{j}=\beta_{0}+\beta_{1} Y_{t}^{+}+\beta_{2} Y_{t}^{-}+\beta_{3} p o p_{t}+\beta_{4} t+\gamma|c|+\varepsilon_{j}$

where $E F$ is log Ecological Footprint of production for land-use type j, $Y^{+}$is cumulative increases in $\log$ GDP, $Y$ is cumulative decreases in log GDP, pop is log population, $t$ is year, $|c|$ is a vector of dummy variables for each country, and $\varepsilon$ is an i.i.d. error term. 


\section{Box 1. Fixed Effects}

Since the introduction of dummy variables in a fixed effects regression greatly increases the overall number of variables, the standard errors for all coefficients tends to increase (known as a reduction in efficiency). In some cases, this may result in coefficients lowering in significance and reducing the value of the regression.

An alternative known as a random effects model is available. This treats any systematic differences between countries as arising from a random process. Random effects is generally thought to be "efficient" (i.e. lower standard errors), but if the underlying assumption is false, then it will lead to biased estimators for all variables (leading to erroneous results).

Due to its underlying efficiency, therefore, random effects models are preferred if it can be shown that there is no significant change in the values of the coefficients between random and fixed effects models. This analysis can be simply performed via the Hausman-Taylor method, which is included in most modern statistical software packages. 
Two-Stage Least Squares Regression

The model presented above is likely to suffer from serious deficiencies in identifying the true impact of changes in economic output on the Ecological Footprint. More specifically, changes in GDP are likely to be correlated with the error term due to reverse causation (where changes in the Ecological Footprint affect GDP), and omitted variable bias (due to the unintended omission of relevant explanatory variables). In order to test for causality, lagged independent variables (and all other exogenous variables) are used as instruments for those variables; this follows the method used by Caviglia-Harris et al. (2009), except that 5 year lags are used in place of 1 year lags to further eliminate reverse causation. This paper tests separately GDP increases, and decreases, in two-stage least squares regressions, where the first stage is:

$W_{t}=\beta_{0}+\beta_{1} Y_{t-5}^{+}+\beta_{2} Y_{t}^{-}+\beta_{3}$ pop $p_{t}+\beta_{4} t+\varepsilon_{j}$

and the second stage is:

$E F_{j}=\beta_{0}+\beta_{1} W_{t}+\beta_{2} Y_{t}^{-}+\beta_{3} p o p_{t}+\beta_{4} t+\varepsilon_{j}$

where $\mathrm{W}_{\mathrm{t}}$ represents the first stage estimation. 
Box 2. Two-Stage Least Squares and Instrumental Variables

The desired end-result for most regression analyses is to establish a causal relationship between two variables of interest. Unfortunately, this is difficult to obtain in simple regressions: there may be omitted variables that are correlated with both the exogenous and endogenous variables and leading to their correlation with each other.

Suppose a variable could be found that only influences the endogenous variable through its effect on the exogenous variable of interest. A correlation between this (instrumental) variable and the endogenous variable could then be interpreted as proof that the exogenous variable is causing a change in the endogenous variable.

Two-stage least squares (2SLS) provides a way to incorporate this reasoning within a formalized framework. Since it often reduces the efficiency of the regression, however, it is typical to use estimates of significance from simpler methods (such as Ordinary Least Squares), and then use the 2SLS results to determine whether the true causal effects may be larger or smaller than the original estimate.

\section{$\underline{\text { Analysis }}$}

\section{Autocorrelation and Heteroskedasticity}

Autocorrelation is often a problem in data sets that contain time series. This occurs when there are likely to be unexplained variables contained within the error term, so the error term will be correlated with time rather than constant. 
One of the assumptions underlying the use of least squares regression is that the unexplained error term $(\mathrm{u})$ has a constant variance. However, it is often the case that the variance in the error term is correlated with some of the independent variables and therefore non-constant. If this heteroskedasticity goes uncorrected, it will result in altered variances for the coefficients, and may lead to unnecessary acceptance or rejection of their significance.

Due to problems in estimating autocorrelation in autoregressive models (Gujarati, 2003), and to correct for any heteroskedasticity present, the HAC robust estimations of the standard errors suggested by Arellano are presented (Arrelano, 2003).

\section{Testing for Asymmetry with Linear Restrictions}

Suppose that $\beta^{+}$represents the coefficient for an income increase and $\beta^{-}$represents the coefficient for an income decrease. To determine whether there is asymmetry, it should be examined whether allowing $\beta^{+}$and $\beta^{-}$to differ gives the model significantly more explanatory power than if they were forced to be equal.

To do this, the model was estimated using the restriction that $\beta^{+}+\beta^{-}=0$, and tested for whether there was a significant decrease in explanatory power. The F-statistic is defined as:

$$
F=\frac{\left(S S R_{R}-S S R_{U R}\right) / q}{S S R_{U R} /(n-k-1)}
$$

where $S S R_{R}$ is the sum of squared residuals from the restricted model, $S S R_{U R}$ is the sum of squared residuals from the unrestricted model, $\mathrm{q}$ is the number of restrictions, $\mathrm{n}$ is the 
number of observations, and $\mathrm{k}$ is the number of independent variables in the unrestricted model. $\mathrm{F}$ is distributed as a random variable with $(\mathrm{q}, \mathrm{n}-\mathrm{k}-1)$ degrees of freedom.

\section{RESULTS}

At the 95 percent confidence level, the null hypothesis of no effect on the Ecological Footprint of changes in GDP for cropland, fishing grounds, carbon, and builtup land is rejected. For no land-use type is the null hypothesis rejected for both GDP increases and decreases (Table 2).

The fixed effects regression suggests that a 1 percent increase in GDP is associated with a 0.14 percent increase in the fishing grounds Footprint, and a 0.24 percent increase in the carbon Footprint. However, the 2SLS model suggests that the fixed effects regression is producing estimates lower than the causal relationship would suggest (Table 3 ), and that the true values may be closer to 0.28 percent and 0.43 percent respectively.

Conversely, the fixed effects model suggests that a 1 percent decrease in GDP is associated with a 0.1 percent decrease in the cropland Footprint, and a 0.07 percent decrease in the built-up land Footprint. Again, the 2SLS model suggests these are underestimates (Table 4), with the true values being closer to 0.15 percent and 0.08 percent respectively.

The null hypothesis of symmetric effects of changes in GDP can only be strongly rejected for the carbon Footprint (Table 2), though in most cases this is due to the large standard errors rather than any apparent symmetry in the coefficients. 
Table 2. Fixed effects estimation of impact on the Ecological Footprint of production by changes in GDP, with significance of asymmetric impacts. Robust standard errors given in parentheses.

\begin{tabular}{llllllll}
\hline \hline & Cropland & Grazing & Forest & Fishing & Carbon & Built ${ }^{1}$ & Total \\
\hline GDP increase & 0.026 & -0.011 & 0.005 & $0.169^{* *}$ & $0.163 * * *$ & 0.030 & $0.051^{* *}$ \\
& $(0.019)$ & $(0.039)$ & $(0.034)$ & $(0.074)$ & $(0.056)$ & $(0.019)$ & $(0.026)$ \\
GDP decrease & $-0.091^{* *}$ & 0.015 & -0.004 & -0.068 & $-0.096^{* *}$ & $-0.073 * * *$ & -0.024 \\
& $(0.037)$ & $(0.019)$ & $(0.023)$ & $(0.053)$ & $(0.037)$ & $(0.019)$ & $(0.022)$ \\
Year & 0.003 & $-0.017 * * *$ & 0.002 & 0.008 & $0.009 *$ & -0.004 & $0.008^{* *}$ \\
& $(0.003)$ & $(0.005)$ & $(0.004)$ & $(0.010)$ & $(0.005)$ & $(0.004)$ & $(0.004)$ \\
Population & $0.954 * *$ & $1.063 * * *$ & $0.452 * * *$ & $1.033 * * *$ & $1.102 * * *$ & $1.130 * * *$ & $0.624 * * *$ \\
& $(0.134)$ & $(0.198)$ & $(0.168)$ & $(0.388)$ & $(0.221)$ & $(0.160)$ & $(0.139)$ \\
\hline \# of obs. & 4954 & 4591 & 4639 & 4936 & 4963 & 4445 & 5057 \\
R-squared & 0.285 & 0.127 & 0.160 & 0.248 & 0.469 & 0.469 & 0.432 \\
\# of clusters & 168 & 155 & 159 & 170 & 170 & 148 & 173 \\
\hline p-asymmetric & 0.154 & 0.985 & 0.471 & 0.416 & $0.003 * * *$ & 0.206 & $0.049 * *$ \\
\hline \hline
\end{tabular}

* significant at $10 \%$;* significant at $5 \%$; ** significant at $1 \%$

${ }^{1}$ Hausman test indicates that random effects estimator is not biased; however for consistency with other land-use types, the fixed effects estimation has been retained

Table 3. 2-stage Least Squares estimation, using 5-year lagged GDP increase as an instrument for GDP increase. Country dummies included in regression but not shown.

\begin{tabular}{llllllll}
\hline \hline & Cropland & Grazing & Forest & Fishing & Carbon & Built & Total \\
\hline GDP increase & $-0.179 * * *$ & $0.129 * * *$ & $-0.355^{* * *}$ & $0.455^{* * *}$ & $0.389^{* * *}$ & -0.003 & $-0.054^{*}$ \\
& $(0.025)$ & $(0.026)$ & $(0.033)$ & $(0.064)$ & $(0.045)$ & $(0.020)$ & $(0.032)$ \\
GDP decrease & $-0.140 * * *$ & $0.038^{* * *}$ & $-0.096^{* * *}$ & $-0.044^{* *}$ & $-0.062^{* * *}$ & $-0.075^{* * *}$ & $-0.024^{* *}$ \\
& $(0.007)$ & $(0.008)$ & $(0.010)$ & $(0.019)$ & $(0.013)$ & $(0.006)$ & $(0.010)$ \\
Year & $-0.008^{* * *}$ & $-0.019 * * *$ & -0.002 & $0.009 * * *$ & -0.004 & -0.001 & $0.003 *$ \\
& $(0.001)$ & $(0.001)$ & $(0.002)$ & $(0.003)$ & $(0.002)$ & $(0.001)$ & $(0.002)$ \\
Population & $1.830 * * *$ & $0.770 * * *$ & $1.651^{* * *}$ & $0.356^{* * *}$ & $1.235^{* * *}$ & $1.061 * * *$ & $1.173 * * *$ \\
& $(0.035)$ & $(0.020)$ & $(0.025)$ & $(0.048)$ & $(0.034)$ & $(0.015)$ & $(0.024)$ \\
\hline \# of obs. & 4631 & 4295 & 4350 & 4617 & 4639 & 4157 & 4732 \\
R-squared & 0.988 & 0.989 & 0.980 & 0.931 & 0.959 & 0.988 & 0.976 \\
\hline \hline
\end{tabular}

* significant at $10 \% ; * *$ significant at $5 \% ; * * *$ significant at $1 \%$ 
Table 4. 2-stage Least Squares estimation, using 5-year lagged GDP decrease as an instrument for GDP decrease. Country dummies included in regression but not shown.

\begin{tabular}{llllllll}
\hline \hline \multirow{2}{*}{ GDP increase } & Cropland & Grazing & Forest & Fishing & Carbon & Built & Total \\
& $-0.241 * * *$ & $0.067 * * *$ & $-0.156 * * *$ & 0.032 & $-0.171 * * *$ & $-0.121 * * *$ & $-0.048 * *$ \\
GDP decrease & $(0.018)$ & $(0.021)$ & $(0.026)$ & $(0.046)$ & $(0.033)$ & $(0.015)$ & $(0.023)$ \\
& $-0.092 * * *$ & $0.129 * * *$ & $-0.303 * * *$ & $0.192 * * *$ & $0.244 * * *$ & $0.060 * * *$ & -0.010 \\
Year & $(0.018)$ & $(0.019)$ & $(0.025)$ & $(0.045)$ & $(0.033)$ & $(0.014)$ & $(0.023)$ \\
& $-0.008 * * *$ & $-0.019 * * *$ & -0.003 & $0.020 * * *$ & $0.011 * * *$ & -0.001 & 0.003 \\
Population & $(0.001)$ & $(0.001)$ & $(0.002)$ & $(0.003)$ & $(0.002)$ & $(0.001)$ & $(0.002)$ \\
& $1.831 * * *$ & $0.760 * * *$ & $1.641 * * *$ & $0.199 * * *$ & $1.060 * * *$ & $1.041 * * *$ & $1.175 * * *$ \\
& $(0.040)$ & $(0.022)$ & $(0.027)$ & $(0.052)$ & $(0.038)$ & $(0.016)$ & $(0.025)$ \\
\hline \# of obs. & 4194 & 3890 & 3941 & 4173 & 4199 & 3781 & 4273 \\
R-squared & 0.989 & 0.988 & 0.981 & 0.938 & 0.959 & 0.988 & 0.977 \\
\hline \hline
\end{tabular}

Within the projections that follow, the results from the 2SLS regression are used for changes in GDP, provided the original coefficients were significantly different from zero at the 95 percent confidence level.

\section{$\underline{\text { Projection }}$}

Detailed results for all countries are presented in Appendix C. On aggregate, the global Ecological Footprint is projected to reach more than 19 billion global hectares by 2012 (compared to 18.2 billion gha in 2008), and more than 20 billion gha by 2016 . In per capita terms, a 0.7 percent drop is expected to be reflected in the National Footprint Accounts between 2008 and 2009 due to the total Ecological Footprint growing more slowly than population (Figure 3). 


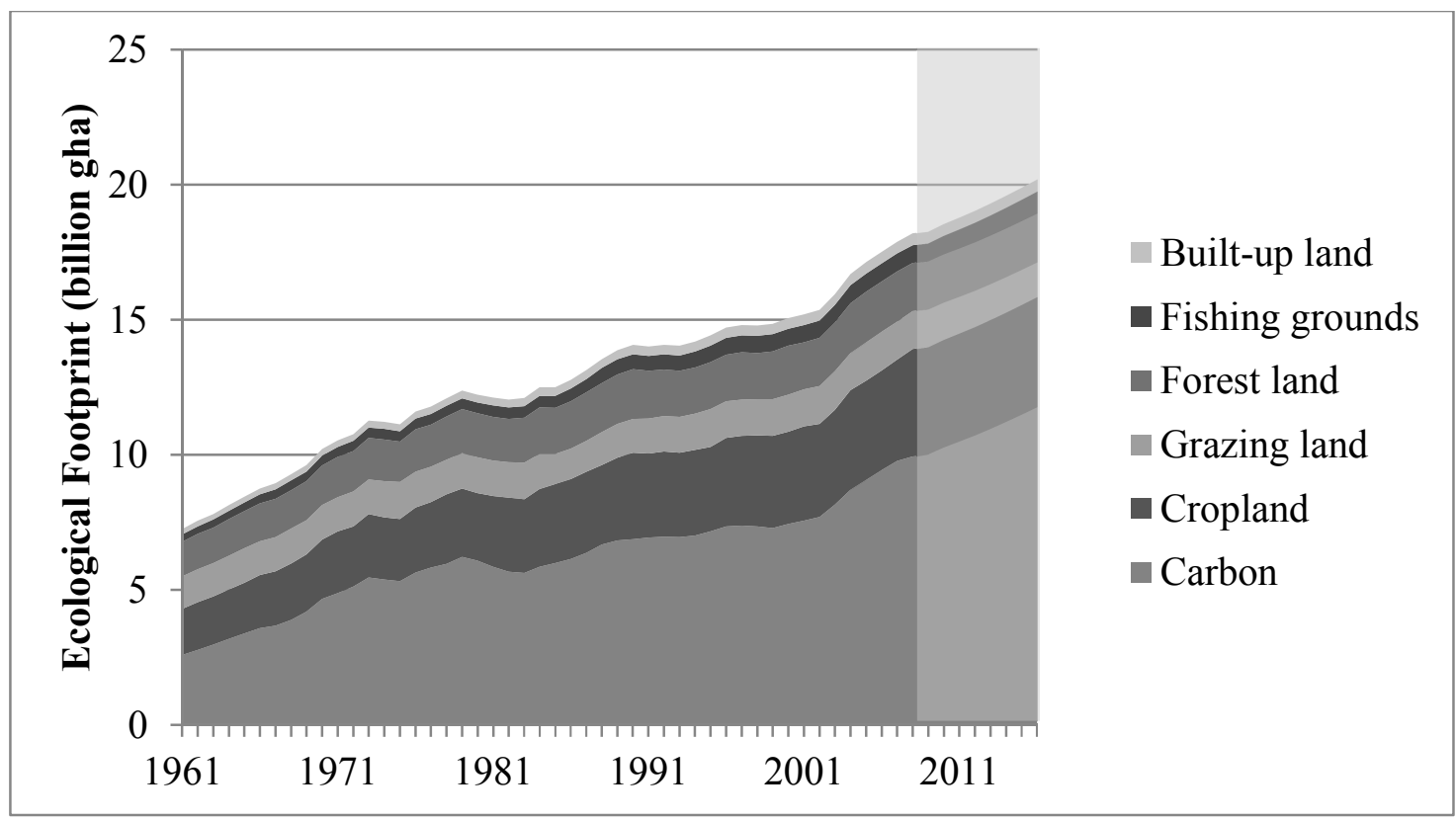

Figure 2. Historical and projected (grey area) global total Ecological Footprint, projected using asymmetric effects of changes in economic output.

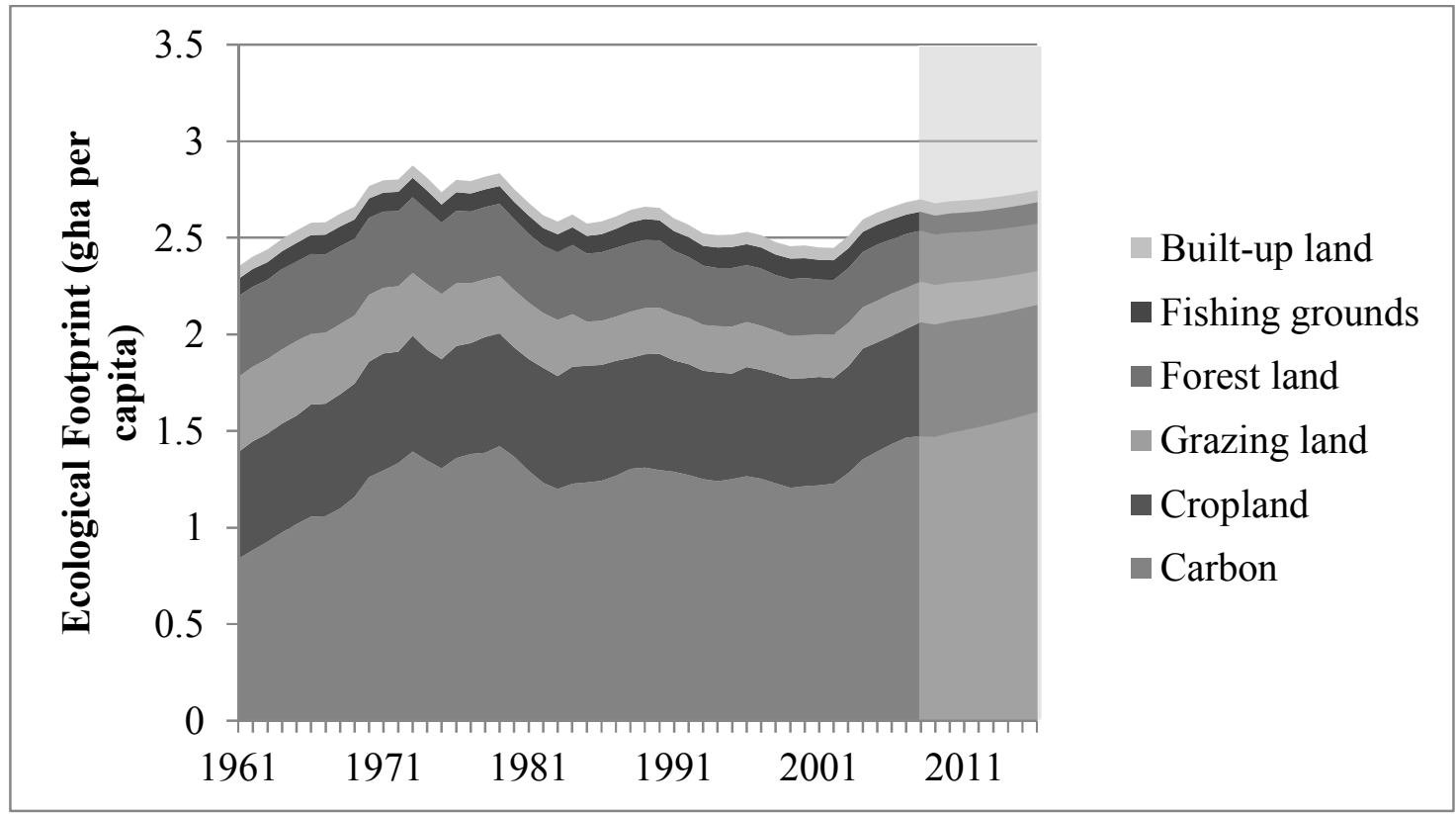

Figure 3. Historical and projected (grey area) global Ecological Footprint per capita, projected using asymmetric effects of changes in economic output. 
For the remainder of the projection period the per capita Footprint is expected to continue growing, reaching 2.76 gha by 2016 (a 2 percent increase over 2008).

Underlying these changes are continued shifts in the composition of the Ecological Footprint, with 59 percent being comprised of carbon by 2016 (up from 55 percent in 2008); by 2016 only 6 percent is expected to come from grazing land ( 8 percent in 2008). These results are summarized in Table 5.

Table 5. The percentage composition of the Ecological Footprint in 2008 and (projected) in 2016

\begin{tabular}{lcc}
\hline \hline Land-use Type & 2008 & 2016 \\
\hline Cropland & 21.9 & 20.2 \\
Grazing land & 7.7 & 6.3 \\
Forest land & 9.8 & 8.9 \\
Fishing grounds & 3.6 & 4.1 \\
Carbon & 54.6 & 58.3 \\
Built-up land & 2.4 & 2.2 \\
\hline \hline
\end{tabular}




\section{PART III: LONG-TERM ECOLOGICAL FOOTPRINT PROJECTIONS USING ESTIMATES FROM INTERNATIONAL AGENCIES}

\section{INTRODUCTION}

Despite a proliferation of future scenarios, many models used for projections for the future are based upon assumptions that are readily criticized, and the results thereby dismissed. There is, therefore, a need for a relatively simple, consistent scenario tool that avoids the use of extensive modeling and, by use of transparent model equations, simply translates accepted projections into Ecological Footprint and biocapacity terms.

International agencies, such as the United Nations and the International Energy Agency, frequently release their own projections forthe future but these are focused on narrow spheres of interest. Since the Global Footprint Network's National Footprint Accounts(NFA) are structured to monitor the combined impact of anthropogenic pressures more typically evaluated independently (Reed, Galli and Wackernagel 2010), they already present a framework for combininghistorical datasets (Ewing et al., 2008). This framework can thus be extended to utilize future projections of these datasets, and, as explored here, may be used to determine whether these independently constructed scenarios are compatible with each other.

An analysis at the global level, as performed here, has associated limitations to policy relevance due to the lack of country-level resolution. Nevertheless, this method has been used as an extensible framework to successfully analyze scenarios in the world 
Business Council's Vision 2050 report (WBCSD, 2010), as well as the 2010 Living Planet Report (WWF International, 2010).

\section{METHODS}

\section{Constant Global Hectares}

The long-term scenario projection covers a time span of nearly 90 years, from 1961 to 2050 . As a result, the large changes in land productivity and land-use are likely to cause difficulties in making time series comparisons and associations with the data reported by international organizations (Reed, Galli and Wackernagel 2010). For example, if world yields on all land-use types were to double from their present value, the standard measure of biocapacity would show no increase; a measure that relates specifically to the quantity of products that can be derived from the land would be much more useful.

In order to negotiate this challenge, intertemporal yield factors (Reed, Galli and Wackernagel 2010) are used as an adjustment to standard Ecological Footprint yield factors, resulting in a constant global hectare analysis, where a unit mass of a primary product has an equal biocapacity value across all years. The historical Ecological Footprint time series are therefore calculated as follows:

$E F=\sum_{i} \frac{P_{N, i, j}}{Y_{N, i, j}} \cdot Y F_{N, j} \cdot I Y F_{N, j} \cdot E Q F_{j}$

where $\mathrm{P}$ is the amount of any given product, i, harvested (or CO2 emitted) in a given year $\mathrm{j}, \mathrm{Y}$ is the product specific yield, the subscripts $\mathrm{N}$ and $\mathrm{W}$ denote national and world 
values, and YF, IYF, and EQF denote yield factors, intertemporal yield factors, and equivalence factors, respectively. Historical biocapacity is also calculated in terms of constant global hectares as:

$B C=A_{N, j} \cdot Y F_{N, j} \cdot I Y F_{N, j} \cdot E Q F_{j}$

where $\mathrm{A}$ is the physical area occupied by the land-use type. For products $\mathrm{i}$ in a given year $\mathrm{j}$, with a selected base year $\mathrm{b}$, IYF is calculated as:

$I Y F_{N, j}=\frac{\sum_{i}\left(\frac{P_{N, i, j}}{Y_{W, i, b}}\right) \cdot E Q F_{j}}{\sum_{i}\left(\frac{P_{N, i, j}}{Y_{W, i, j}}\right) \cdot E Q F_{j}}$

For the projections, the Footprint of an individual product is determined by multiplying the mass quantity of the product by its Footprint Intensity (I):

$I=\frac{E F_{W, i}}{P_{W, i}}$

\section{$\underline{\text { Data Sources }}$}

Projection data have been drawn from international sources including the Food and Agriculture Organization (FAO), United Nations Population Division (UNPD), International Energy Agency (IEA), and the Intergovernmental Panel on Climate Change (IPCC). All data not already disaggregated were converted into per capita values, using the UNPD median variant estimate if not otherwise indicated. Table 1 summarizes these sources. Projections of food consumption by category were taken from FAO (FAO 2006), adjusted so that historical FAO food consumption data matched historical National 
Footprint Accounts (NFA) data, and converted to physical cropland and grazing land areas and global hectares (gha) as per Eq. ( 8 ). Baseline yields were taken to be constant in the absence of high quality projections. Consumption of fish was estimated using projected capture quantities (FAO 2008). Projections of total power demand by fuel/source were taken from IEA, according to their baseline estimates (IEA 2008). These were converted into total carbon emissions and net carbon emissions using carbon intensity and Carbon Capture and Storage data (IEA 2008). These net emissions were then converted into gha according to Eq. ( 8 ). Forest product consumption estimates and forest yields were obtained from a WBCSD participating company. Built land areas were projected using a constant physical area required per person. Biocapacity estimates were endogenous to the model, and were primarily a function of changes in land-use due to demand for cropland and grazing land. The influence of a non-constant environment through climate change was accounted for through the modification of land suitability (FAO/IIASA 2000). Net carbon emissions data were interpreted through the best-guess climate sensitivities from the IPCC to get an effective projected temperature increase (Solomon, et al. 2007). This temperature increase is then passed through FAO's GAEZ model to give an impact on land suitability and the consequent effect on agricultural yields. 
Table 6. Summary of exogenous variables used in the long-term scenario projections

\begin{tabular}{|c|c|c|}
\hline Variable & Options & Source \\
\hline $\begin{array}{l}\text { Energy production, } \\
\text { quantity, and mix }\end{array}$ & $\begin{array}{l}\text { A. Baseline } \\
\text { B. ACT map } \\
\text { C. BLUE map }\end{array}$ & (IEA 2008) \\
\hline Food consumption & $\begin{array}{l}\text { V. FAO projection } \\
\text { W. US } 2005 \text { value } \\
\text { X. Italy } 2005 \text { value } \\
\text { Y. Costa Rica } 2005 \text { value } \\
\text { Z. Malaysia } 2005 \text { value }\end{array}$ & $\begin{array}{l}(\text { FAO 2006) } \\
(\text { FAO 2010) }\end{array}$ \\
\hline Population & $\begin{array}{l}\text { a. Low variant } \\
\text { b. Medium variant } \\
\text { c. High variant } \\
\text { d. Constant fertility variant }\end{array}$ & (UNDESA 2008) \\
\hline Forest yields & $\begin{array}{l}\text { i. Constant } \\
\text { ii. WBCSD projection }\end{array}$ & \\
\hline Crop yields & $\begin{array}{l}\text { I. Constant } \\
\text { II. WBCSD projection }\end{array}$ & \\
\hline Climate change & $\begin{array}{l}\text { 1. None } \\
\text { 2. IPCC } \\
\text { 3. Hadley }\end{array}$ & $\begin{array}{l}\text { (Solomon, et al. 2007) } \\
\text { (Hulme, et al. 1999) }\end{array}$ \\
\hline Livestock feed mix & $\begin{array}{l}\text { world Agriculture Towards } \\
2030 / 2050\end{array}$ & (FAO 2006) \\
\hline Fisheries capture & $\begin{array}{l}\text { The State of world Fisheries } \\
\text { and Aquaculture }\end{array}$ & (FAO 2008) \\
\hline
\end{tabular}

\section{Land-use Projections}

The Ecological Footprint consists of six different land-use types: cropland, grazing land, forest land, carbon uptake land, fishing grounds and built-up land. Biocapacity is comprised of five land-use types; identical to those included in the Ecological Footprint with the exception of carbon uptake land. As mentioned above, biocapacity estimates were endogenous to the model; the biocapacity section below 
describes the calculation of biocapacity in more detail. The long-term scenario projections operate under the assumption that, given a limited land supply, demand for cropland takes priority over grazing land, and demand for grazing land takes priority over forest land. Therefore, the biocapacity for grazing land is equal to the greater of the remaining land after crop, built, and forest demands have been met.

\section{Cropland}

The cropland Footprint is calculated based on total food and fiber crop harvests. Food demand is calculated on a per capita basis, while fiber crop demand is input as a global total. Food demand is divided into eight categories used in "world Agriculture Towards 2030/2050" (FAO 2006) (cereals, roots and tubers, sugar, pulses, vegetables and oils, meat, milk and dairy, other food) and an additional category for fish.

All food categories except fish have an associated cropland demand, either for primary consumption or for livestock fodder. Total tons demanded, D, of each food type, $\mathrm{f}$, is calculated as the product of: P (total population); CI (per capita caloric intake); and R (the percentage of total caloric intake expected to be met by a particular food type). Since the input data is expressed in terms of final consumption, the fraction of production that is "wasted" (i.e. not consumed) needs to be determined. Using the most recently available "wastage ratio" from 2003, derived by dividing the production quantity by the consumption quantity, the tons of consumed product are converted into production tons. The food categories' total tonnages are multiplied by their respective Footprint intensities (see Eq. ( 11 )), expressed in gha $\mathrm{t}-1$, and summed to give total cropland Footprint (EFcrop). The use of biofuels is excluded at this point, due to a lack of accepted 
projections for their use and primary feedstocks. Initial estimates, as used in some publications, suggest that their inclusion could result in a Footprint about 4 percent higher by 2050 (WWF 2010). Cropland area is endogenous in the calculations; it is determined on the basis of total food demand divided by crop yields and provides insight on the area of cropland that will be required in the future to meet humanity's demand for crop related food. Any growth in required cropland area implies land-use changes and is deducted from the land area available for other land cover types in the biocapacity calculations. Cropland is a special case within the land covers considered in the Footprint, in that supply and harvest are by definition equal.

\section{Grazing land}

The Ecological Footprint for grazing land is calculated based on the demand for animal products, the feed required per unit of each livestock category, and the amount of feed met by crop products. The meat consumption is disaggregated into bovine, ovine, poultry, and pigmeat based on projected growth in the FAO's "Agriculture Towards 2030/2050" document (FAO 2006). As with crops, these demand quantities are converted into production quantities using the 2003 ratios between production and consumption quantities. The production quantities are then multiplied by the Feed Efficiency (tons feed per ton of meat) derived from the 2008 National Footprint Accounts (Ewing, et al. 2008) to give the total amount of feed demanded. By subtracting the FAO's projections of the percentage increase in crop based feed per year from the total feed needed, the feed that must be met from grazing lands can be derived. The 
Ecological Footprint is equal to this number multiplied by the Footprint intensity for grass.

\section{Forest land}

The total timber harvest projections given by a WBCSD member company were divided by the UN Medium population projections (UNDESA 2008) to determine per capita harvest. This is simply multiplied by the population projections selected and the Footprint intensity of timber to arrive at total forest land Footprint. The calculation of forest land biocapacity divides forests into three categories: primary forests, modified natural forests, and planted productive forests, with a yield and area for each. The total Net Annual Increment (NAI) for all forest areas is multiplied by the Footprint intensity of timber to determine total biocapacity. However, if the demand for grazing land increases beyond its biocapacity, the area of forest will be reduced accordingly (with a proportionate decline across all forest types).

\section{Carbon uptake land}

The "area equivalent" of carbon dioxide emissions is calculated as the area of world-average forest land that would be required to take up emissions at the same rate at which they are produced, after subtracting out a percentage due to sequestration by the ocean. This ocean sequestration factor is assumed to remain constant at 2005 levels due to limited projections on how this will change. Only emissions from energy-uses are currently considered in the model. Total global energy demand is a user-specified input (converted into per capita numbers as with forest land), which is subdivided into energy- 
use for transportation, for electrical generation and for other applications. The proportion of total energy-use for each consumption type is specified for a variety of fuels, yielding the total energy demand by fuel type. These demand quantities are multiplied by the fuels' respective carbon intensities to yield total carbon emissions. Projected emissions reductions from carbon capture and storage are subtracted from global total emissions (IEA 2008), and the difference is multiplied by the Footprint intensity of carbon emissions to arrive at the demand for carbon uptake land. Yield increases for carbon uptake (i.e. changes in the rate of forest uptake) are already accounted for in the calculation of forest land biocapacity.

\section{Fishing grounds}

The Footprint for fishing grounds is calculated by converting per capita demand to a total harvest amount, in a manner similar to the other food categories. The default per capita demand is inferred from projections of total fish consumption (FAO 2008) and per capita caloric intake (FAO 2006). This total catch quantity is then multiplied by the average Footprint intensity of all the 2005 catch. This assumes that the average trophic level of caught fish does not change substantially. Aquaculture is not included, since most of the inputs to aquaculture operations are already tallied elsewhere in the model.

The FAO projections show declining catches over time (FAO 2008), indicating that stocks are collapsing. The long-term scenario projections do not attempt to model these collapses, and thus under scenarios in which demand for fish increases, the model will show biocapacity rising to meet that demand. 


\section{Built-up land}

The total area of built-up land is exogenous to the model. The default scenario assumes that the worldwide extent of built-upland will grow by 0.023 ha for each additional person. Since built-upland is not available for other uses, the biocapacity occupied by our built environment will always be exactly equal to its Footprint.

\section{Biocapacity}

By model definition, the biocapacity for cropland, fishing grounds, and built-up land are equal to the Ecological Footprint. In order to determine the grazing land and forest land biocapacity, the following preliminary steps were taken: For the reference year, 2005, the distribution of land at various suitability levels was taken from the GAEZ database (FAO/IIASA 2000), where the suitability is expressed as the expected rain-fed crop yields as a fraction of the highest yield found worldwide. This physical quantity of land was then scaled to an equivalent area of perfect suitability:

$\mathrm{A}^{\mathrm{s}}=\mathrm{A} \cdot \mathrm{fs}$

where $\mathrm{A}$ is the actual area of land under each suitability category, and fs is the suitability index assigned by GAEZ. For example, 10 ha of land with a suitability index of 0.1 are equal to 1 ha of perfect suitability land. The demanded area of cropland and built-up land is distributed across A, and the relative area of As needed is determined by assuming that cropland and built-up land are distributed across the highest productivity land possible on a global scale. The average suitability of land occupied by cropland and built-up land in 2005 was thus determined to be 0.83 . This value was assumed to hold constant throughout the projections, so that 
$\mathrm{A}_{\mathrm{C}}^{\mathrm{s}}=\mathrm{A}_{\mathrm{C}} \cdot 0.83$

where $\mathrm{A}_{\mathrm{C}}^{\mathrm{s}}$ is the area of cropland and built-up land at suitability $1, \mathrm{~A}_{\mathrm{C}}$ is the physical area of land-used for cropland and built-up land. For all years, $\mathrm{A}_{\mathrm{C}}^{\mathrm{s}}$ was subtracted from the most suitable land available. The remaining land, $\mathrm{A}^{\mathrm{s}}-\mathrm{A}_{\mathrm{C}}^{\mathrm{s}}$, was marked as available for forest and grazing land.

\section{Forest land biocapacity}

Forest land is assumed to occupy the most suitable land once cropland and builtup land demands are accounted for. Where there was sufficient land to accommodate it, projected forest area (sourced from WBCSD member company) was used in the determination of biocapacity. In cases where the projected built-up land, cropland, and grazing land areas were larger than allowed for by these forest land projections could not be met, forest cover was assumed to be limited to the available area. In certain scenarios, the physical area demanded for forest products then exceeds the available area. In this case, a flag is raised to alert the user that the scenarios for forest product demands are unlikely to be met.

\section{Grazing land biocapacity}

Once the area used for forest land was subtracted, the total remaining area of land with a suitability index of 0.1 or higher was assumed to be grazing land.

\section{Non-constant land-use suitability}

As we look towards the future and our impacts and demands upon the Earth's resources, it is expected that there will be a change in the distribution of land-use types. 
Additionally, there are changes in the underlying suitability of the land that these landuses occupy. In this analysis, the sole driver of changes in the suitability of land-used for human purposes is warming through anthropogenic greenhouse gas emissions. The total carbon dioxide emissions in 2005 reported in the National Footprint Accounts were converted to a fractional change in the reported carbon dioxide concentration in the atmosphere (Tans 2010). This conversion factor, 0.074ppm increase per billion tons carbon dioxide, was then used to convert the projected emissions under each scenario. The best estimate climate forcing under these concentrations (Solomon, et al. 2007) was used to derive a temperature projection, and the consequent changes in land suitability were determined (FAO/IIASA 2000). Since the changes in land suitability are only projected up to a 3 degree rise, the linear rate of change between 2 and 3 degree rises was extrapolated to account for higher emissions scenarios.

\section{RESULTS}

The baseline estimates (Table 6:A, V, b, i, I, 2) project humanity's Ecological Footprint to increase to over 31 billion gha (in 2005 constant gha) by 2050 ( 3.4 gha per capita). The composition of the Ecological Footprint would be similar to that of today, with approximately $60 \%$ coming from the carbon Footprint component (Figure 4). Total biocapacity would rise through 2030 , peaking at 12.6 billion gha (1.5 gha per capita) largely due to the effects of increased availability of land suitable for agriculture due to the initial effects of climate change. Total biocapacity then decreases as the climate warms further, reaching 11.9 billion in 2050 (1.3 gha per capita). 
As land becomes constrained, agricultural land is given preference over forest land and forest biocapacity drops from 4.5 to 2.6 billion gha between 2030 and 2050 (Figure 5). These effects combine to give projections where humanity requires the regenerative and absorptive capacity of 2 Earths by 2033 and over 2.6 Earths by 2050 . In comparison, if humanity followed the IEA's BLUE map scenario (Table 6: C, V, b, i, I, 2) (requiring emissions to stabilize at $50 \%$ of 2005 levels by 2050) but kept other consumption (such as food, fiber, etc.) and yield estimates at the baseline, humanity would require less of the Earth's capacity by 2050 than it does now, at just under 1.5 times the resources and ecological services provided by the Earth (Figure 6).

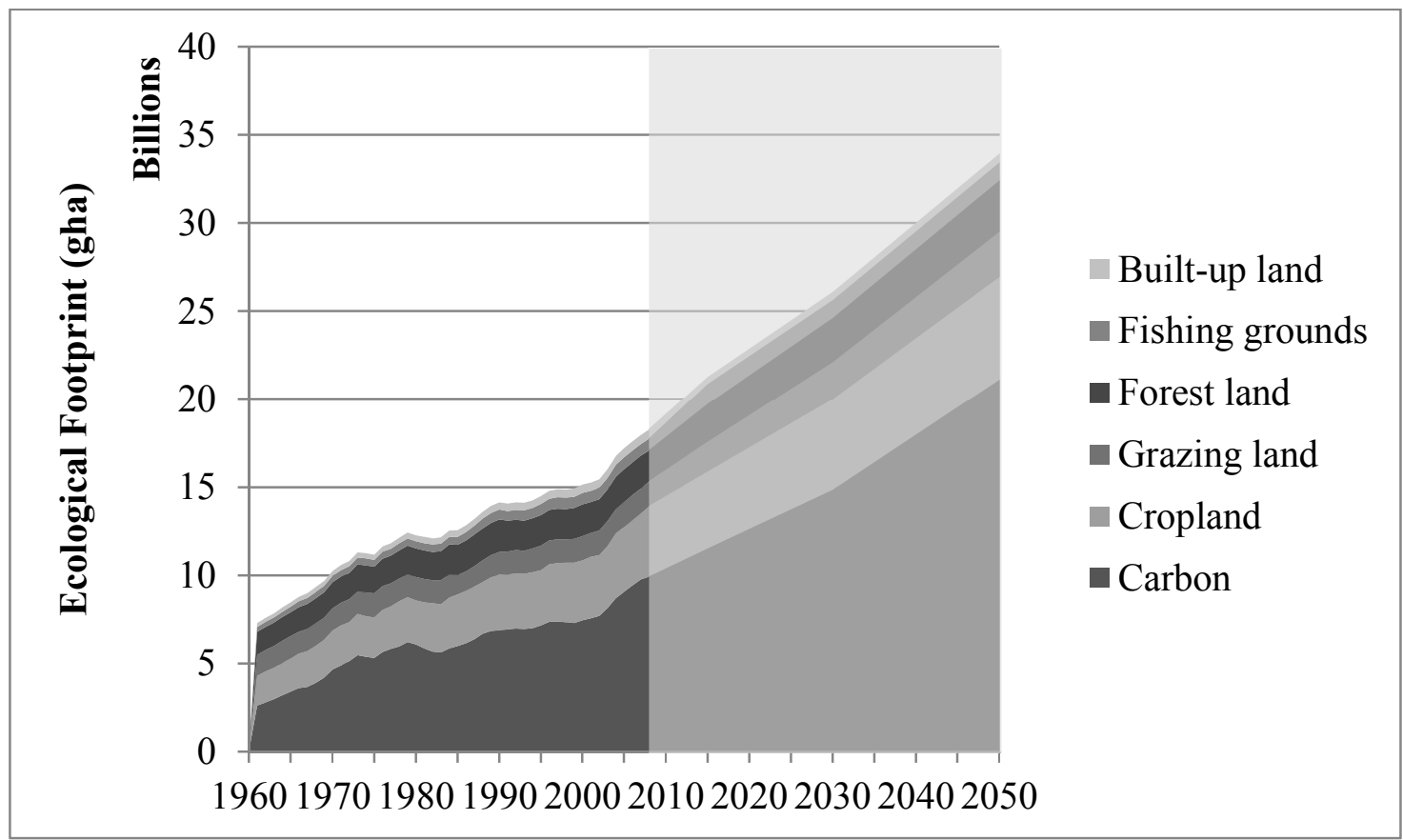

Figure 4. Historical and projected (shaded area) global Ecological Footprint using longterm baseline scenario projections. 


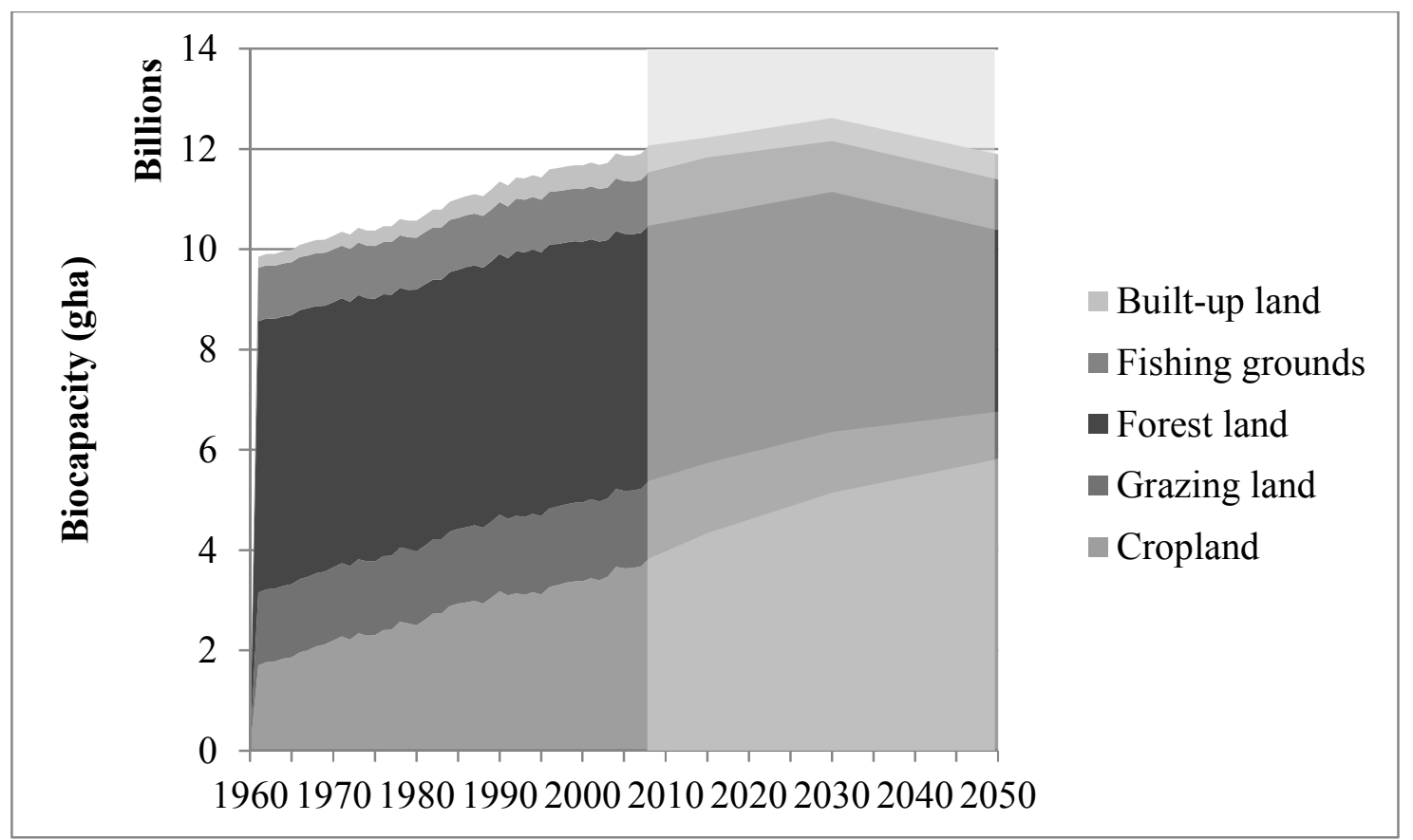

Figure 5. Historical and projected (grey area) global biocapacity using long-term baseline scenario projections. These include the baseline IEA projection for carbon emissions ( $62 \mathrm{Gt}$ annually by 2050); FAO projection for food consumption by 2050 (3130 calories produced per person); UN median variant for population growth $(9.2$ billion by 2050); constant forest and crop yields; and the IPCC B2 model of how carbon emissions translate into temperature changes. 


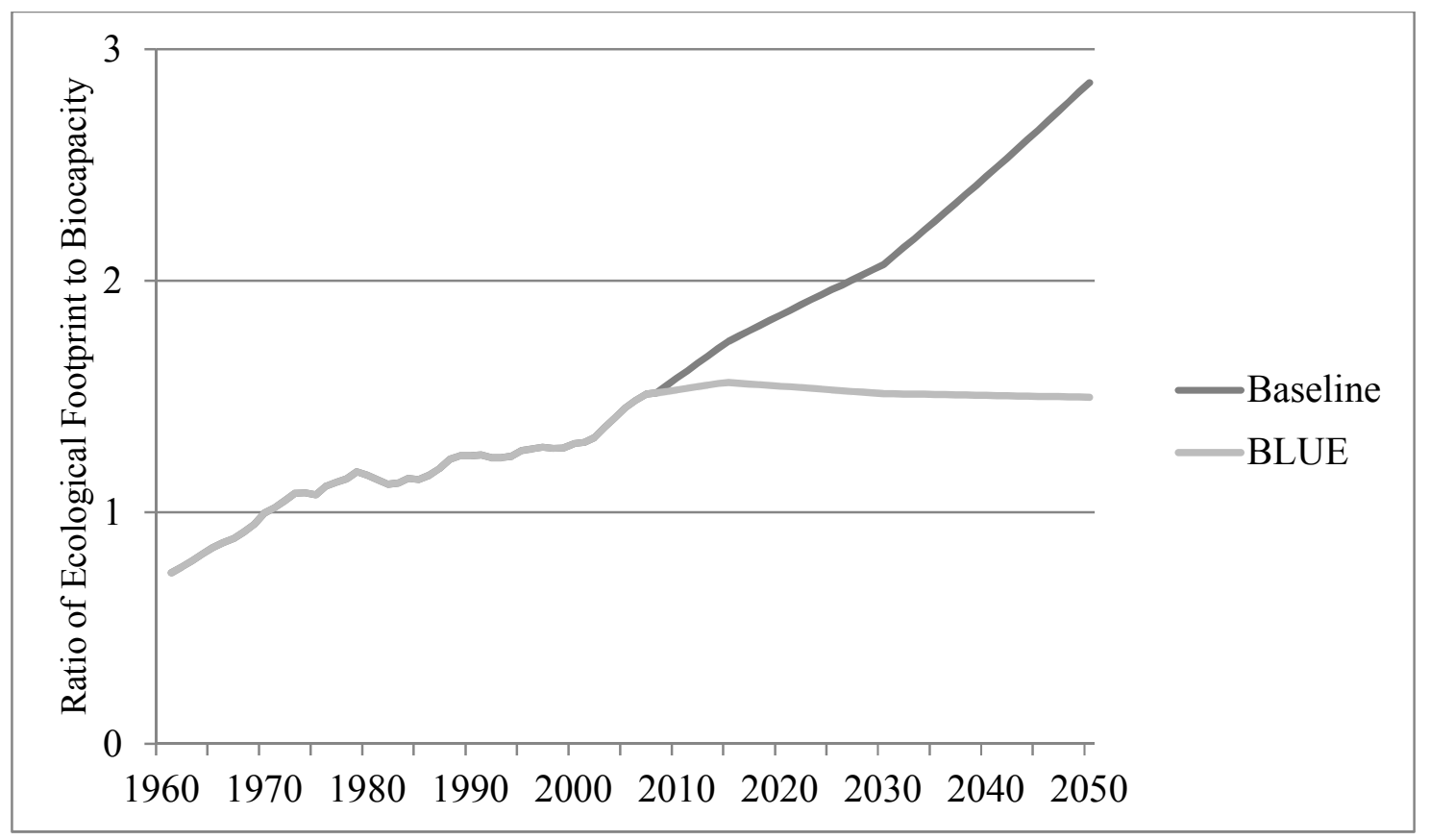

Figure 6. Comparison of the Ecological Footprint to biocapacity ratio for BLUE map and baseline scenarios.

In 2015 , the calculated physically available area of forest was about 3.9 billion hectares, while the quantity of forest products demanded requires an area of 1.5 billion hectares to supply it. However, by 2050, the demands require an area of 2.7 billion hectares while only 2.0 billion hectares are available, due to expansion of cropland and grassland. This highlights one interesting conflict in projections from international organizations: that we cannot meet the projected food and forest product demands under the projected yield scenarios. Therefore, planning based on these projections may be subject to serious flaws. Since food demand is the greatest driver of land-use change in the calculations, it is informative to look at what effects a movement towards different global average food consumption levels would have. The FAO's projection is for the 
global average caloric consumption to rise to $3130 \mathrm{kcal} /$ person/day by 2050 , with about $17.5 \%$ coming from meat and dairy products (FAO 2006). In contrast, in 2005 the US was consuming $3753 \mathrm{kcal} /$ person/day with $27.8 \%$ from meat and dairy; Malaysia was consuming $2883 \mathrm{kcal} /$ person/day with $12.0 \%$ from meat and dairy (FAO 2010). Figure 7 shows the projected impacts on the Ecological Footprint from achieving these various dietary patterns as a global average by 2050 .

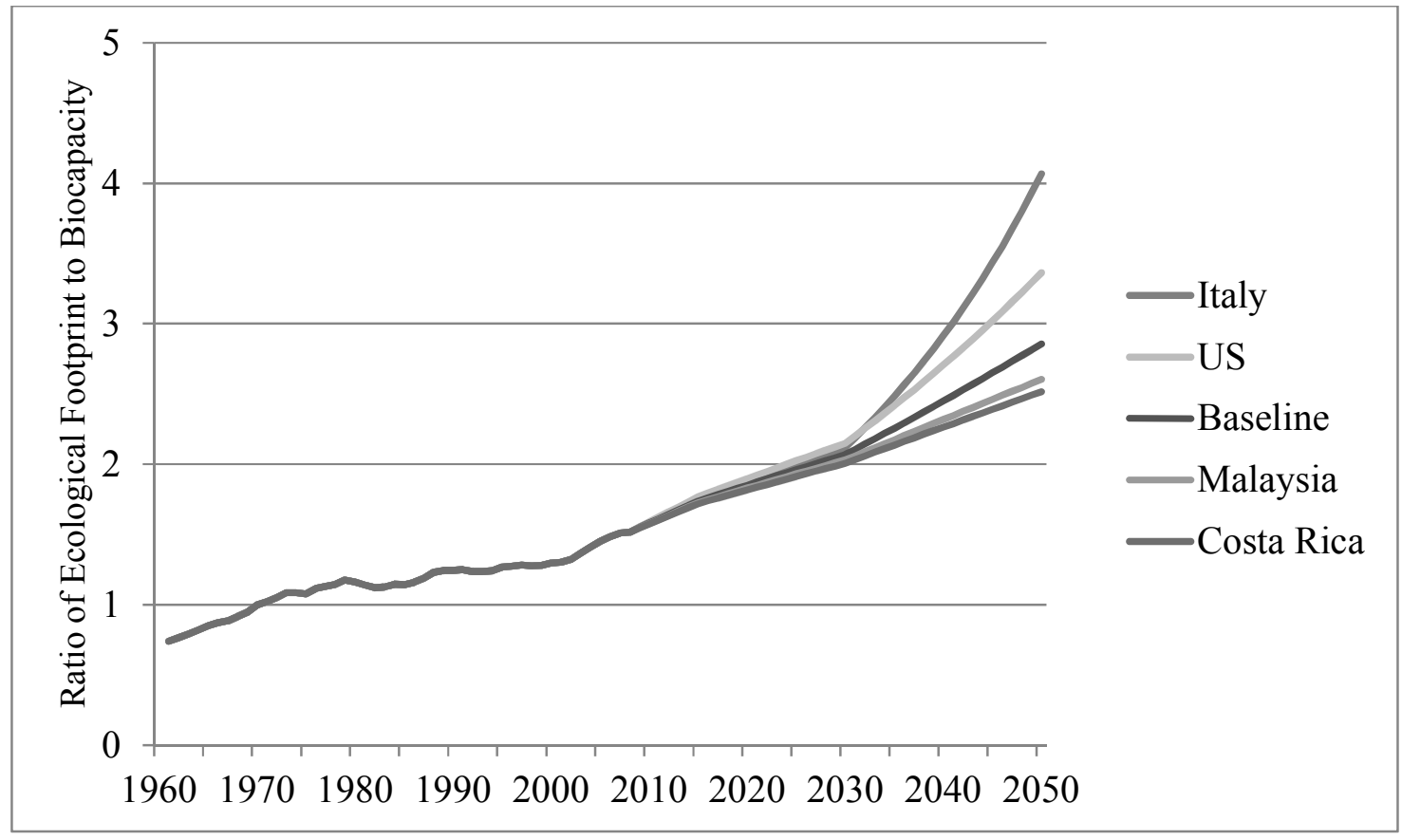

Figure 7. Comparison of the impact of dietary patterns on the Ecological Footprint.

Finally, in an attempt to derive a scenario that projects a reduction of the Ecological Footprint below one planet's biocapacity by 2050, the best case projections are used (Table 6: C, Y, a, ii, II, 2). Note that the climate change effects are included, because under the emissions projections used here, warming tends to increase the suitability of land for growing crops. Figure 8 illustrates that result, showing that 
meeting aggressive goals on all fronts is just sufficient to bring resource consumption and waste production, as measured by the Ecological Footprint, to within the global capacity to supply it.

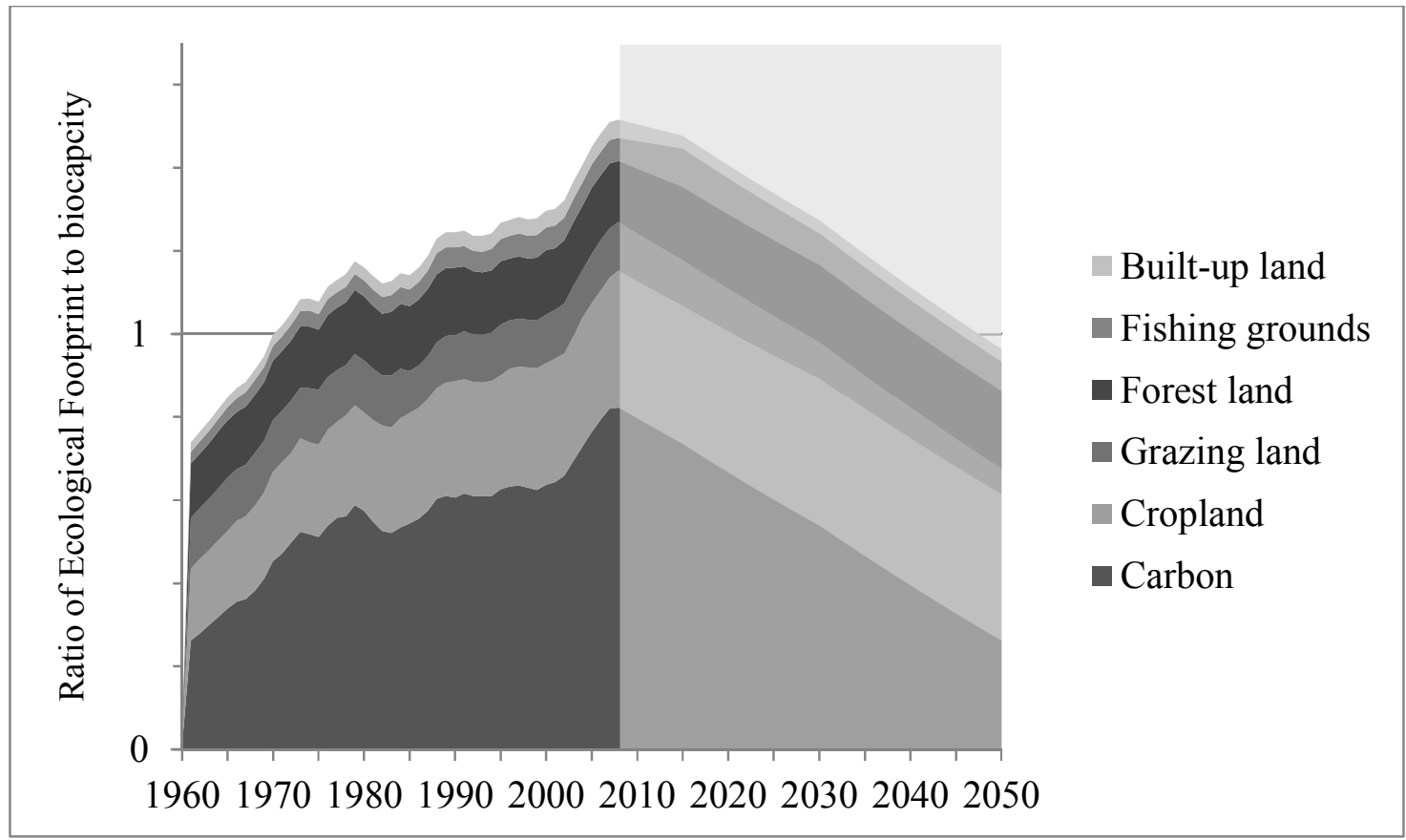

Figure 8. The Ecological Footprint to biocapacity ratio for the most aggressive Footprint reduction scenario. This includes the IEA BLUE Map scenario (14 Gt annually by 2050); Costa Rican levels of global food consumption in 2050 (2812 calories produced per person); the UN low variant estimate of population (7.8 billion by 2050); WBCSD member company projections of forest and crop yields (a tripling of forest plantation yields, and about a 30\% increase in crop yields); IPCC B2 estimates of the impact of carbon emissions on temperature changes. 


\section{PART IV: EVALUATION OF METHODS FOR ECOLOGICAL FOOTPRINT PROJECTIONS}

\section{COMPARISON}

The projection methods used here are relatively simple, consistent, and extendable. The short-term projection method provides a simpler, more transparent framework, and allows for yearly resolution. The long-term projection method allows for greater user flexibility in assessing alternative pathways, but this comes at the expense of simplicity and resolution.

Unsurprisingly, the projections start to diverge early; already by 2015 (the only year for which we have results for both methods in which the long-term projection is not interpolated), the projected Ecological Footprint differs by 6 percent (2.75 gha per capita for the short-term method; 2.91 gha per capita for the long-term projection). Some of this difference may be explained by the global recession from 2007 onwards, which was not captured in any of the independent sources used for the long-term projection.

The short-term projection method has already found use in the determination of the Global Footprint Network's "Overshoot Day,” the day in each year in which humanity has already used the entire year's supply of biocapacity. Prior to this research, Overshoot Day analysis was simply calculated through a linear regression of world Ecological Footprint against world GDP: the greatly increased resolution and sophistication of the method used here likely gives a much more accurate estimate. In addition, there has been interest from WWF International in using the methodology to 
present country-level results that have been "nowcasted" to the current year, rather than typical results that are three years in arrears.

The long-term scenario methods have found success through the world Business Council's Vision 2050 project, and have since been used with individual member companies for their own private projections. There is gathering interest to invest in this methodology and attempt to refine it to the country-level so that policy decisions can be based upon it.

\section{CRITICISM}

The short-term Ecological Footprint projections, while providing high resolution estimates of individual countries' Ecological Footprints of production suffer from two main drawbacks: they are highly dependent upon external GDP projections; they do not offer information on the Ecological Footprint of consumption at a country level. The first of these drawbacks is somewhat less important when using the method for "nowcasting:" since GDP is often measured on a quarterly basis with a lag of only one or two periods there is little need for GDP projections. The second drawback is a problem when using the Ecological Footprint for communication purposes, since the public has been trained over the past 8 years that the Ecological Footprint is primarily a consumption based

measure. Extension of the methods used here to look at the Ecological Footprint of consumption as a function of national income may help to rectify this.

The long-term Ecological Footprint scenario projections were found to be sufficiently adequate in translating independent projections into comprehensive 
Ecological Footprint and biocapacity terms. In doing so, they highlight any inconsistencies in these projections and thus encourages additional research into how future demands could be met in the presence of competing interests. A fundamental assumption is the priority given to certain land types: demand for grazing land takes precedence over demand for forest land; demand for cropland takes precedence over grazing land. While this is a necessary assumption here, it means that specific areas of shortage in the future are hidden and simply show up as inadequate forest areas. In reality, the price shifts seen under conditions of shortage will change consumption preferences; it may be that forest products become of higher preference than grazed animal products. Due to a narrow range of temperatures used in the dataset of the suitability of land for human use under warming conditions, extrapolation was necessary. With the presence of multiple feedback effects in the climate, extrapolations are likely to severely misestimate future conditions. Inherent in the framework of the model, built, as it is, upon other macro scale projections, is the inability to look at how certain modifications in key economic or demographic variables will alter the Ecological Footprint. Breaking apart the individual projection modules into key variables would assist in determining key drivers.

For example, underlying the population projections are variables regarding fertility and mortality: incorporating these variables will allow this module to break free of the four pre-defined United Nations projections. Perhaps most significantly, the structure of the long-term scenario projections is unsuitable for anything beyond cursory implementation at the national level: at this scale, trade patterns become crucial in 
determining whether demands can be met, socioeconomic driving forces become of increasing importance, and projections of changes in land suitability given changes in greenhouse gas emissions are difficult to source or are contradictory.

\section{FUTURE IMPROVEMENTS}

\section{Economic Modeling}

Following on from the work on Wassily Leontief (Leontief 1970) examinations of how the Ecological Footprint of a country is driven by the consumption pattern of final consumers within an economy have been performed (Wiedmann, et al. 2006). While the derived Ecological Footprint from such an environmentally Extended Input-Output analysis (EEIO) will differ from the current National Footprint Accounts due to a number of factors, 5 these types of estimation are extremely useful in modeling due to the establishment of economy-environment linkages. Use of EEIO in modeling can take a number of forms. The medium-term environmental impacts of large government expenditures in certain sectors can be traced: from the initial increase in Ecological Footprint required to supply the increased demand; to the additional wages, taxes, and profits formed; to the knock-on effects these have in spurring additional demand.

The impact of certain policies, such as income taxes and income redistribution can be tracked through their effects on household and government income (and thus expenditures), given a set of income elasticities. Direct taxes on or subsidies for certain sectors including the substitution of monetary flows for physical flows for imports and exports, trade of embodied non-carbon Ecological Footprints in commodities, and the 
incorporation of trade in services will alter the demand for that sector's output based on established price elasticities. Incorporating these policy options within the model clearly offers a tool of much greater utility than one that relies upon simple external projections, though for many countries input-output tables of sufficiently high resolution are difficult to obtain.

\section{Dynamic Modeling}

While the refinements discussed above lend additional credibility to scenario projections and allow greater resolution in determining the effect of individual policies, they still rest upon the assumption that the governments already see a link between resource limitations, as measured by the Ecological Footprint, and socio-economic wellbeing. There have been limited instances of this so far: only a handful of countries (such as the United Arab Emirates and Ecuador) have undertaken concrete commitments to limiting the size of the Ecological Footprint. There are two potential areas for expanding this type of analysis to make it more relevant for all countries: expanding the indicators used and incorporating feedback loops. The economic model discussed above is not indicator specific; any environmental indicator that can be allocated to the industrial sectors that place direct pressure on them can be analyzed. For example, there is the potential for looking at pressure on biodiversity through the allocation of tropical deforestation to sectors that place these demands.

It is in the incorporation of feedback loops that even greater relevance can be brought to bear on policy makers. There is a general conceptual awareness that wealth is 
critically dependent upon the use of natural resources and their modification through human labor and energy (Adams 2006). To date, there have been no quantified links between an increase in the Ecological Footprint and increased negative economic or social consequences. However, there is a much greater likelihood of establishing quantitative links between more disaggregated indicators, such as the pressure on deforestation due to unsustainable demands on forest resources, and economic and social well-being. With the incorporation of these links, where the ability to extract forest products may decrease in the future and lead to price increases for forest products, we can establish a truly dynamic model. Despite the many levels of complexity that this will bring, such models will truly help both guide policy and solidify the relevance of environmental factors in socio-economic debates.

Addressing the global sustainability challenge requires assessing and managing the trade-offs between guaranteeing human well-being in the short-term and preserving the Earth's regenerative capacity in the long-term. Constructing believable scenarios of humanity's future path is thus fraught with difficulties and can be subject to much criticism. Despite this, major international institutions have seen fit to construct models to assess current policies and identify areas of potential limitations to current trends.

By using a variety of these models, and placing them into the Ecological Footprint framework, we can not only determine a plausible projection of future demands on the Earth's ecosystems, but also highlight areas where institutional projections are incompatible with each other. The conceptually simple model presented here already highlights that increased caloric demands for food are incompatible with maintained 
forest areas in a warming environment. Expanding the available options for scenarios based on global policies and disaggregating the analysis to national or regional levels are critical improvements that must be made in order to make this a useful planning tool. 


\section{REFERENCES}

Adams, W. M. The future of sustainability: Re-thinking environment and development in the twenty-first century. Gland, Switzerland: IUCN, 2006.

Arnell, N. W. "Climate change and global water resources: SRES emissions and socioeconomic scenarios." Global Environmental Change 14, no. 1 (2004): 31-52.

Bagliani, M., G. Bravo, and S. Dalmazzone. "A consumption-based approach to environmental Kuznets curves using the ecological footprint indicator." Ecological Economics 65 (2008): 650-661.

Barkmann, J., et al. "Confronting unfamiliarity with ecosystem functions: the case for an ecosystem service approach to environmental valuation with states preferences methods." Ecological Economics 65, no. 1 (2008): 48-62.

Caviglia-Harris, J. L., D. Chambers, and J. R. Kahn. "Taking the "U" out of Kuznets: A comprehensive analysis of the EKC and envrionmental degradation." Ecological Economics 68 (2009): 1149-1159.

Chay, K., and M. Greenstone. "The impact of air pollution on infant mortality: Evidence from geographic variation in pollution shocks induced by a recession." Quarterly Journal of Economics 118 (2003): 1121.

Cherp, A., and R. Mnatsakanian. "Environmental degradation in Eastern Europe, Caucasus, and Central Asia: past roots, present transition and future hopes." In Eastern Europe, Russia and Central Asia, by Imogen Gladman. London: Routledge, 2003.

Ching, R.C.P., W.H. Ip, and S.L. Chan. "An ARIMA-Intervention Analysis Model for the Financial Crisis in China's Manufacturing Industry." International Journal of Engineering Business Management 1, no. 1 (2009): 15-18.

Cranston, G. R., and G. P. Hammond. "North and south: regional footprints on the transition pathway towards a low carbon, global economy." Applied Energy 87, no. 9 (2010): 2945-2951.

de Bruyn, S. M., and J. B. Opschoor. "Developments in the throughput-income relationship: theoretical and empirical observations." Ecological Economics 20 (1997): 255.

de Bruyn, S. M., J. C. J. M. van den Bergh, and J. B. Opschoor. "Economic growth and emissions: reconsidering the empirical basis of Environmental Kuznets curves." Ecological Economics 25 (1998): 161.

DeFries, R. S., J. A. Foley, and G. P. Asner. "Land-use choices: balancing human needs and ecosystem function." Frontiers in Ecology and the Environment 2, no. 5 (2004): 249-257.

DeFries, R. S., L. Bounoua, and G. J. Collatz. "Human modification of the landscape and surface climate in the next fifty years." Global Change Biology 8 (2002): 438-458. 
Dietz, T., E. A. Rosa, and R. York. "Driving the human ecological footprint." Frontiers in Ecology and the Environment 5 (2007): 13-18.

Ellis, E. C., K. K. Goldewijk, S. Siebert, D. Lightman, and N. Ramankutty. "Anthropogenic transformation of the biomes, 1700 to 2000." Global Ecology and Biogeography 19, no. 5 (2010): 589-606.

Ewing, B., A. Reed, A. Rizk, A. Galli, M. Wackernagel, and J. Kitzes. Calculation methodology for the National Footprint Accounts, 2008 edition. Oakland: Global Footprint Network, 2008.

FAO. FAOSTAT. 2010. http://faostat.fao.org/site/562/default.aspx (accessed November $13,2010)$.

FAO. The state of world fisheries and aquaculture. Rome: FAO Fisheries and Aquaculture Department: Food and Agriculture Organization, 2008.

FAO. World Agriculture: towards 2030/2050. Rome: Global Perspectives Studies Unit: Food and Agriculture Organization, 2006.

FAO/IIASA. Global Agro-Ecological Zones. Vienna, Austria: International Institute for Applied Systems Analysis, 2000.

Ferng, J. J. "Applying input-output analysis to scenario analysis of ecological footprints." Ecological Economics 69 (2009): 345-354.

Foley, J. A., et al. "Global consequences of land use." Science 309 (2005): 570-574.

Galli, A., T. Wiedmann, E. Ercin, D. Knoblauch, B. Ewing, and S. Giljum. "Integrating Ecological, Carbon, and Water footprint into a "Footprint Family" of indicators: definition and role in tracking Human Pressure on the Planet." Ecological Indicators, In Press.

Gately, D., and H Huntington. "The asymmetric effects of changes in price and income on energy and oil demand." Energy Journal 23 (2002): 19.

Giddings, B., B. Hopwood, and G O'Brien. "Environment, economy and society: Fitting them together into sustainable development." Sustainable Development 10 (2002): 187.

Grossman, G., and A. Krueger. "Economic growth and the environment." Quarterly Journal of Economics 110 (1995): 353-77.

Hafele, W. Energy in a finite world: A global systems analysis. Cambridge, MA: Ballinger Publishing Company, 1981.

Hulme, M., et al. "Climate change scenarios for global impact studies." Global Environmental Change 9, no. S1 (1999): S3-S19.

IEA. Energy Technology Perspectives 2008 — scenarios and strategies to 2050. Paris: IEA, 2008. 
IMF. World Economic Outlook Database. 2011.

http://www.imf.org/external/pubs/ft/weo/2011/01/weodata/index.aspx (accessed December 8, 2011).

Lenzen, M., T. Wiedmann, B. Foran, C. Dey, A. Widmer-Cooper, and M. Williams. Forecasting the Ecological Footprint of nations: A blueprint for a dynamic approach. Sydney, Australia: Centre for Integrated Sustainablility Analysis at the University of Sydney, 2007.

Leontief, W. "Environmental repercussions and the economic structure: an input-output approach." The Review of Economics and Statistics 52, no. 3 (1970): 262-271.

Mäler, K. "National accounts and environmental resources." Environmental and Resource Economics 1, no. 1 (1991): 1-15.

Mattila, T. "Any sustainable decoupling in the Finnish economy? A comparison of the pathways and sensitivities of GDP and ecological footprint 2002-2005." Ecological Indicators 16 (2012): 128-134.

Moore, D., and A. Galli. The future of the mediterranean: Tracking Ecological Footprint trends. Oakland, CA: Global Footprint Network, 2010.

Mork, K. A. "Oil and the macroeconomy when prices go up and down: An extension of Hamilton's results." Journal of Political Economy 97 (1989): 740-744.

Murtishaw, S., and L. Schipper. "Disaggregated analysis of US energy consumption in the 1990s: evidence of the effects on the internet and rapid economic growth." Energy Policy 29 (2001): 1335.

Nakicenovic, N., et al. Special report on emissions scenarios: A special report of working group III of the Intergovernmental Panel on Climate Change. Cambridge: Cambridge University Press, 2000.

Pilkey, O. H., and L. Pilkey-Jarvis. Useless arithmetic: Why environmental scientists can't predict the future. New York: Columbia University Press, 2007.

Popp, D. C., R. G. Newell, and A. B. Jaffe. "Energy, the environment, and technological change." NBER Working Paper Series, Vol. w14832. April 2009.

Postma, T.J.B.M., and F. Liebl. "How to improve scenario analysis as a strategic management tool?" Technological Forecasting and Social Change 72, no. 2 (2005): $161-173$

Ramankutty, N., and J. A. Foley. "Estimating historical changes in global land cover: croplands from 1700 to 1992." Global Biogeochemical Cycles 13, no. 4 (1999): 9971027.

Ramankutty, N., J. A. Foley, and N. J. Olejniczak. "People on the land: changes in global population and croplands during the 20th century." Ambio 31, no. 3 (2002): 251-257.

Reed, A., A. Galli, and M. Wackernagel. "Inclusion of intertemporal yield factors in time series Ecological Footprint assessments." In The State of the Art in Ecological Footprint 
Theory and Applications, by S. Bastiononi, 131-132. Siena, Italy: Ecodynamics Group, University of Siena, 2010.

Ringland, G. Scenarios in public policy. Indianapolis, US: Wiley, 2002.

Rockström, J., et al. "Planetary boundaries: exploring the safe operating space for humanity." Ecology and Society 14, no. 2 (2009): 32.

Rothman, D. "Environmental Kuznets curves - real progress or passing the buck? A case for consumption-based approaches." Ecological Economics 25 (1998): 177.

Rounsevell, M. D., I. Reginster, M. B. Araújo, T. R. Carter, N. Dendoncker, and F. Ewert. "A coherent set of future land use change scenarios for Europe." Agriculture, Ecosystems \& Environment 114, no. 1 (2006): 57-68.

Ruhm, C. J. "Are recessions good for Your health?" Quarterly Journal of Economics 115 (2006): 617.

Schmidhuber, J., and F. Tubiello. "Global food security under climate change." Proceedings of the National Academy of Sciences 104, no. 50 (2007): 19703-19708.

Selden, T., and D. Song. "Environmental quality and development: Is there a Kuznets Curve for air pollution emissions?" Journal of Environmental Economics and Management 27, no. 2 (1994): 147.

Shafik, N., and S. Bandyopadhyay. Economic growth and environmental quality: Timeseries and cross-country evidence. World Bank Policy Research Working Paper, Washington DC: World Bank, 1992.

Solomon, S., et al. "Contribution of working group I to the fourth assessment report of the Intergovernmental Panel on Climate Change." 2007.

Tans, P. NOAA/ESRL. 2010. www.esrl.noaa.gov/gmd/ccgg/trends/.

UNDESA. World Population Prospects: The 2008 revision. New York: United Nations Department of Economic and Social Affairs: Population Division, 2008.

van Vuuren, D. P., and L. F. Bouwman. "Exploring past and future changes in the ecological footprint for world regions." Ecological Economics 52, no. 1 (2005): 43-62.

Vehmas, J., J. Luukkanen, and J. Kaivo-oja. "Linking analyses and environmental Kuznets curves for aggregated material flows in the EU." Journal of Cleaner Production 15 (2007): 1662-1673.

Wackernagel, M., et al. "National natural capital accounting with the ecological footprint concept." Ecological Economics 29, no. 3 (1999): 375-390.

Wackernagel, M., et al. "Tracking the ecological overshoot of the human economy." Proceedings of the National Academy of Science 99 (2002): 9266-9271.

Wackernagel, M., L. Lewan, and C. B. Hansson. "Evaluating the use of natural capital with the ecological footprint." Ambio 28 (1999): 604-612. 
WBCSD. Vision 2050: The new agenda for business. Geneva, Switzerland: WBCSD, 2010.

WEC. Deciding the future: energy policy scenarios to 2050. London: World Energy Council, 2007.

-. Energy for tomorrow's world: The realities, the real options and the agenda for achievement. New York: Palgrave Macmillan, 1993.

Wiedmann, T., J. Minx, J. Barrett, and M. Wackernagel. "Allocating ecological footprints to final consumption categories with input-output analysis." Ecological Economics 56, no. 1 (2006): 28-48.

World Bank. The World Bank Data Portal. 2011. http://data.worldbank.org/ (accessed December 10, 2011).

WWF. Living Planet Report 2006. Gland, Switzerland: WWF International, 2006.

WWF. Living Planet Report 2008. Gland, Switzerland: WWF International, 2008.

WWF. Living Planet Report 2010. Gland, Switzerland: WWF International, 2010. 


\section{APPENDIX A - STATA CODE FOR VARIABLE CREATION}

encode country, gen(country_num)

xtset country_num year, yearly

replace $g d p=" . "$ if $g d p==" N A "$

replace population="." if population=="NULL"

destring, replace

gen 1_gdp=log $(g d p)$

by country_num (year): gen gdp_ch=1_gdp-1_gdp[_n-1]

gen gdp_inc $=0$

replace $g d p \_$inc $=$. if $1 \_g d p==$.

replace gdp_inc $=$ gdp_ch if gdp_ch $>0$

gen gdp_dec $=0$

replace $g d p \_d e c=$. if $1 \_g d p==$.

replace gdp_dec $=g d p \_c h$ if $g d p \_c h<0$

gen gdp_inc_cum $=0$

replace gdp_inc_cum $=$. if $\operatorname{gdp}==$.

gen gdp_dec_cum $=0$

replace gdp_dec_cum $=$. if $\operatorname{gdp}==$.

sort country year

by country (year): replace gdp_inc_cum=gdp_inc_cum[_n-1]+gdp_inc if gdp_inc_cum[_n-1]!=.

by country (year): replace gdp_dec_cum=gdp_dec_cum[_n-1]+gdp_dec if gdp_dec_cum[n-1]!=.

replace gdp_inc_cum $=$. if gdp_inc $==$.

replace gdp_dec_cum $=$. if gdp_inc $==$.

replace gdp_dec_cum $=-$ gdp_dec_cum

foreach varname of varlist cropland grazing forest fishing carbon built eftotal population gdp_inc_cum gdp_dec_cum \{ gen 1_'varname' $=\log \left(\right.$ 'varname' $\left.^{\prime}\right\}$

by country (year): gen lag_1_gdp_inc_cum=1_gdp_inc_cum[n- -5$]$

by country (year): gen lag_1_gdp_dec_cum $=1$ _gdp_dec_cum[n-5]

quietly: tab(country_num), gen(ct) 


\section{APPENDIX B - STATA CODE FOR REGRESSIONS}

foreach varname of varlist cropland grazing forest fishing carbon built eftotal \{ quietly:xtreg 1_'varname'1_gdp_inc_cum 1_gdp_dec_cum year 1_population, re estimates store 'varname'_re

quietly:xttest0

quietly:xtreg 1_'varname'1_gdp_inc_cum 1_gdp_dec_cum year 1_population, fe estimates store 'varname' fe_h

quietly:hausman 'varname'_fe_h 'varname'_re

estimates store 'varname'_hausman

quietly:xtreg 1_varname'1_gdp_inc_cum 1_gdp_dec_cum year 1_population, fe vce(robust)

estimates store 'varname'_fe

quietly:test 1_gdp_inc_cum=-1_gdp_dec_cum, coef

estimates store 'varname'_test

quietly:ivregress 2sls 1_varname' (1_gdp_inc_cum=lag_1_gdp_inc_cum)

1_gdp_dec_cum year 1_population ct*

estimates store 'varname'_iv1

quietly:ivregress 2sls 1_'varname'1_gdp_inc_cum (1_gdp_dec_cum $=$ lag_1_gdp_dec_cum) year 1_population ct*

estimates store 'varname'_iv2

\} 


\section{APPENDIX C - SHORT-TERM COUNTRY PROJECTIONS}

\begin{tabular}{|c|c|c|}
\hline Country & Trend: 1961-2016 & $\begin{array}{l}\text { Percent change: } 2008 \\
\text { to } 2016\end{array}$ \\
\hline Albania & & $4.1 \%$ \\
\hline Algeria & & $11.8 \%$ \\
\hline Angola & & $15.4 \%$ \\
\hline Antigua and Barbuda & & $7.2 \%$ \\
\hline Argentina & & $6.1 \%$ \\
\hline Armenia & & $8.3 \%$ \\
\hline Australia & & $5.4 \%$ \\
\hline
\end{tabular}




\begin{tabular}{|c|c|}
\hline Austria & $3.3 \%$ \\
\hline Azerbaijan & $8.3 \%$ \\
\hline Bahamas & $10.6 \%$ \\
\hline Bahrain & $21.2 \%$ \\
\hline Bangladesh & $13.7 \%$ \\
\hline Barbados & 7.9\% \\
\hline Belarus & $3.8 \%$ \\
\hline Belgium & $6.9 \%$ \\
\hline
\end{tabular}




\begin{tabular}{|c|c|}
\hline Belize & $10.9 \%$ \\
\hline Benin & $12.8 \%$ \\
\hline Bhutan & $2.5 \%$ \\
\hline Bolivia & $2.9 \%$ \\
\hline Bosnia and Herzegovina & $5.3 \%$ \\
\hline Botswana & $-2.9 \%$ \\
\hline Brazil & $0.4 \%$ \\
\hline Brunei Darussalam & $18.7 \%$ \\
\hline
\end{tabular}




\begin{tabular}{|c|c|}
\hline Bulgaria & $1.7 \%$ \\
\hline Burkina Faso & $1.9 \%$ \\
\hline Burundi & $4.3 \%$ \\
\hline Cambodia & $6.7 \%$ \\
\hline Cameroon & $8.5 \%$ \\
\hline Canada & $5.5 \%$ \\
\hline Cape Verde & $26.0 \%$ \\
\hline Central African Republic & $3.5 \%$ \\
\hline
\end{tabular}




\begin{tabular}{|c|c|}
\hline Chad & $-1.8 \%$ \\
\hline Chile & $8.8 \%$ \\
\hline China & $21.7 \%$ \\
\hline Colombia & $0.9 \%$ \\
\hline Comoros & $9.6 \%$ \\
\hline Congo, Democratic Republic of & $8.7 \%$ \\
\hline Congo & $8.9 \%$ \\
\hline Costa Rica & $5.3 \%$ \\
\hline
\end{tabular}




\begin{tabular}{|c|c|}
\hline Croatia & $1.8 \%$ \\
\hline Cyprus & $-6.1 \%$ \\
\hline Czech Republic & $4.9 \%$ \\
\hline Denmark & $3.1 \%$ \\
\hline Djibouti & $5.0 \%$ \\
\hline Dominica & $5.1 \%$ \\
\hline Dominican Republic & $16.1 \%$ \\
\hline Ecuador & $9.8 \%$ \\
\hline
\end{tabular}




\begin{tabular}{|c|c|}
\hline Egypt & $12.1 \%$ \\
\hline El Salvador & $1.3 \%$ \\
\hline Equatorial Guinea & $52.8 \%$ \\
\hline Eritrea & $4.6 \%$ \\
\hline Estonia & $5.4 \%$ \\
\hline Ethiopia & $5.9 \%$ \\
\hline Fiji & $5.5 \%$ \\
\hline Finland & $3.3 \%$ \\
\hline
\end{tabular}




\begin{tabular}{|c|c|}
\hline France & $3.4 \%$ \\
\hline Gabon & $5.5 \%$ \\
\hline Gambia & $13.5 \%$ \\
\hline Georgia & $2.1 \%$ \\
\hline Germany & $2.1 \%$ \\
\hline Ghana & $9.2 \%$ \\
\hline Greece & $1.4 \%$ \\
\hline Grenada & $3.7 \%$ \\
\hline
\end{tabular}




\begin{tabular}{|c|c|}
\hline Guatemala & $7.0 \%$ \\
\hline Guinea & $6.4 \%$ \\
\hline Guinea-Bissau & $7.0 \%$ \\
\hline Guyana & $5.9 \%$ \\
\hline Haiti & $5.7 \%$ \\
\hline Honduras & $7.3 \%$ \\
\hline Hungary & $1.5 \%$ \\
\hline Iceland & $11.3 \%$ \\
\hline
\end{tabular}




\begin{tabular}{|c|c|}
\hline India & $14.5 \%$ \\
\hline Indonesia & $13.9 \%$ \\
\hline Iran, Islamic Republic of & $15.9 \%$ \\
\hline Iraq & $35.7 \%$ \\
\hline Ireland & $3.5 \%$ \\
\hline Israel & $20.3 \%$ \\
\hline Italy & $2.8 \%$ \\
\hline Jamaica & $6.2 \%$ \\
\hline
\end{tabular}




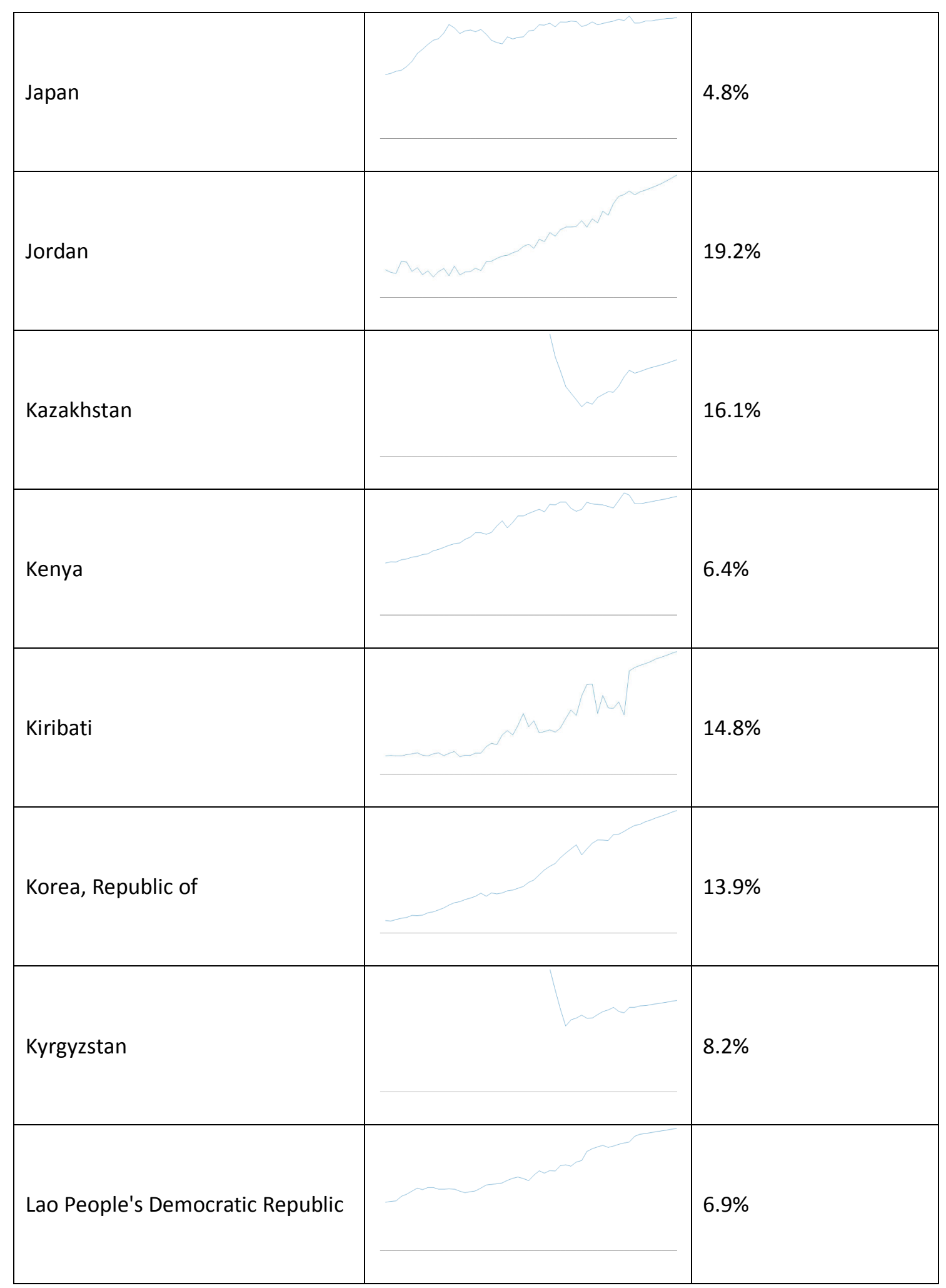




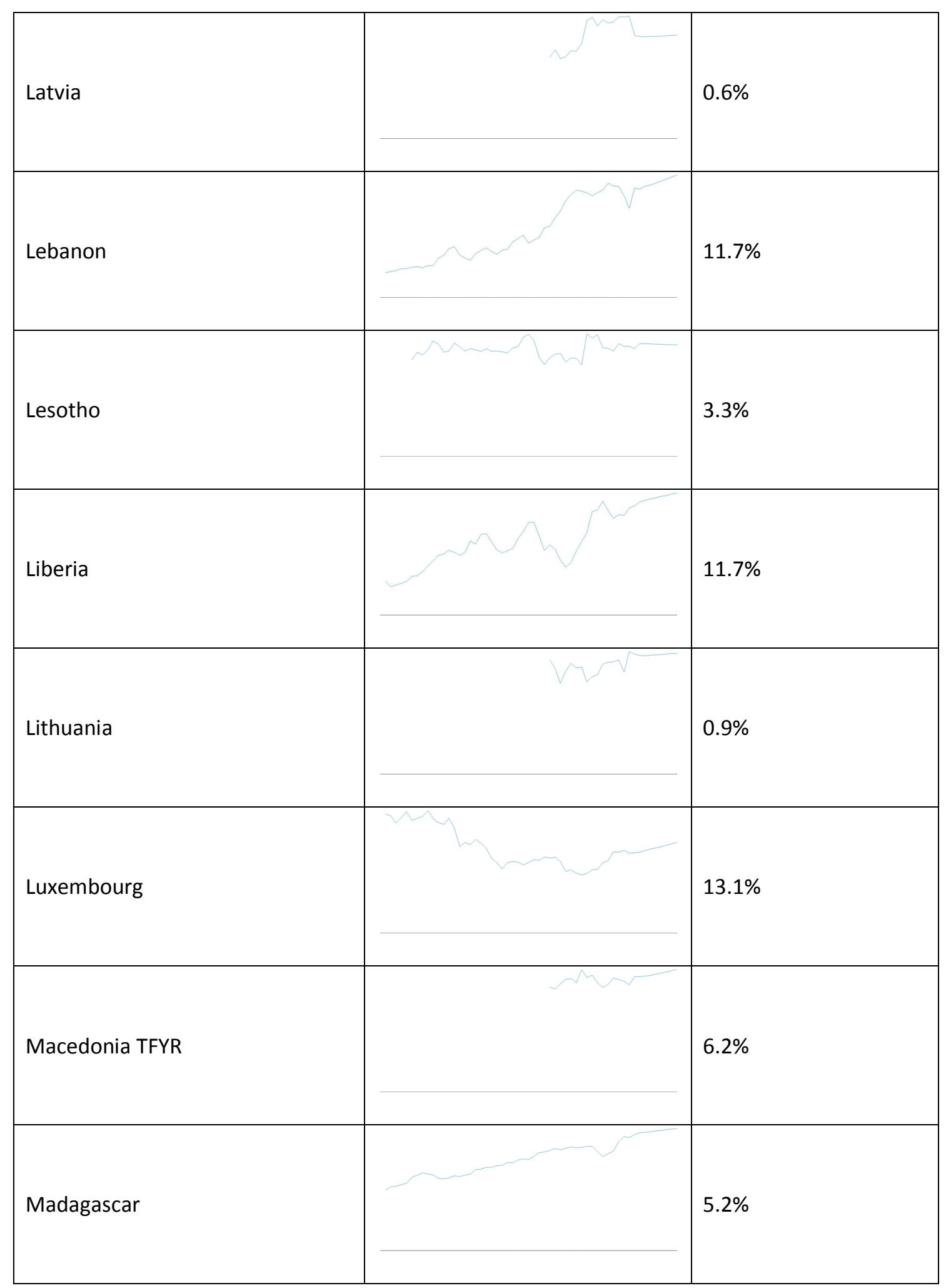




\begin{tabular}{|c|c|}
\hline Malawi & $11.2 \%$ \\
\hline Malaysia & $15.5 \%$ \\
\hline Maldives & $22.9 \%$ \\
\hline Mali & $-1.0 \%$ \\
\hline Malta & $9.5 \%$ \\
\hline Mauritania & $-0.9 \%$ \\
\hline Mauritius & $13.1 \%$ \\
\hline Mexico & $5.8 \%$ \\
\hline
\end{tabular}




\begin{tabular}{|c|c|}
\hline Moldova & $2.4 \%$ \\
\hline Mongolia & $4.3 \%$ \\
\hline Montenegro & $-4.3 \%$ \\
\hline Morocco & $9.0 \%$ \\
\hline Mozambique & $4.5 \%$ \\
\hline Namibia & $4.6 \%$ \\
\hline Nepal & $1.6 \%$ \\
\hline Netherlands & $4.9 \%$ \\
\hline
\end{tabular}




\begin{tabular}{|c|c|}
\hline New Zealand & $2.4 \%$ \\
\hline Nicaragua & $2.1 \%$ \\
\hline Niger & $5.2 \%$ \\
\hline Nigeria & $9.4 \%$ \\
\hline Norway & $8.8 \%$ \\
\hline Oman & $28.3 \%$ \\
\hline Pakistan & $10.8 \%$ \\
\hline Panama & $18.5 \%$ \\
\hline
\end{tabular}




\begin{tabular}{|c|c|}
\hline Papua New Guinea & $19.5 \%$ \\
\hline Paraguay & $1.8 \%$ \\
\hline Peru & $13.1 \%$ \\
\hline Philippines & $16.2 \%$ \\
\hline Poland & $5.7 \%$ \\
\hline Portugal & $1.7 \%$ \\
\hline Qatar & $58.7 \%$ \\
\hline Romania & $1.8 \%$ \\
\hline
\end{tabular}




\begin{tabular}{|c|c|}
\hline Russian Federation & $5.9 \%$ \\
\hline Rwanda & $4.3 \%$ \\
\hline Samoa & $3.3 \%$ \\
\hline Saudi Arabia & $21.6 \%$ \\
\hline Senegal & $12.0 \%$ \\
\hline Serbia & $-7.6 \%$ \\
\hline Seychelles & $21.1 \%$ \\
\hline Sierra Leone & $13.7 \%$ \\
\hline
\end{tabular}




\begin{tabular}{|c|c|}
\hline Singapore & $27.2 \%$ \\
\hline Slovakia & $5.0 \%$ \\
\hline Slovenia & $3.5 \%$ \\
\hline Solomon Islands & $11.0 \%$ \\
\hline South Africa & $10.2 \%$ \\
\hline Spain & $3.3 \%$ \\
\hline Sri Lanka & $11.7 \%$ \\
\hline Sudan & $-10.7 \%$ \\
\hline
\end{tabular}




\begin{tabular}{|c|c|}
\hline Suriname & $16.9 \%$ \\
\hline Swaziland & $-2.5 \%$ \\
\hline Sweden & $2.9 \%$ \\
\hline Switzerland & $5.6 \%$ \\
\hline Syrian Arab Republic & $11.6 \%$ \\
\hline Tajikistan & $12.1 \%$ \\
\hline Tanzania, United Republic of & $2.9 \%$ \\
\hline Thailand & $6.7 \%$ \\
\hline
\end{tabular}




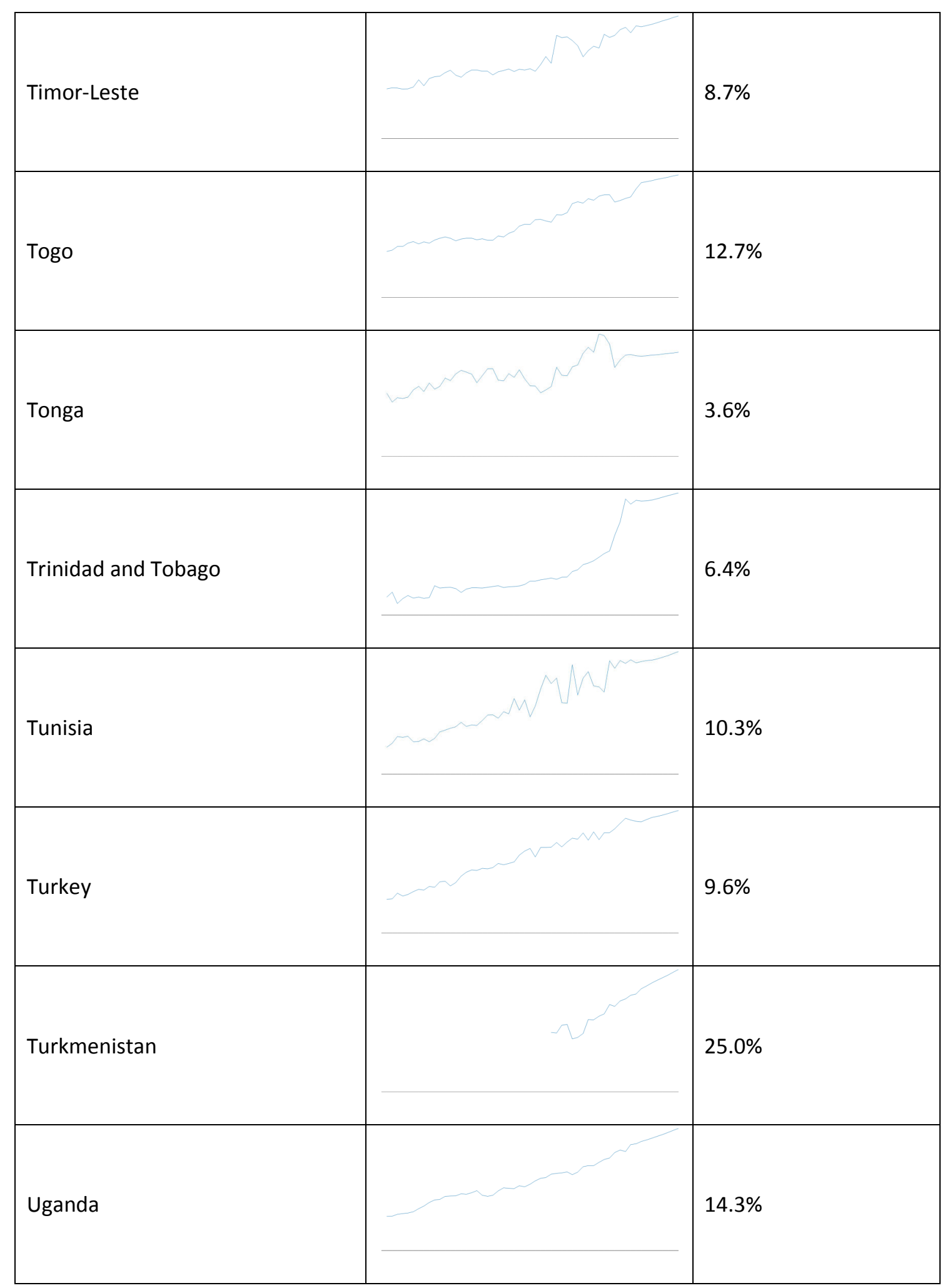




\begin{tabular}{|c|c|}
\hline Ukraine & $3.4 \%$ \\
\hline United Arab Emirates & $-5.1 \%$ \\
\hline United Kingdom & $6.1 \%$ \\
\hline United States of America & $8.0 \%$ \\
\hline Uruguay & $-4.2 \%$ \\
\hline Uzbekistan & $20.5 \%$ \\
\hline Vanuatu & $21.3 \%$ \\
\hline Venezuela, Bolivarian Republic of & $7.6 \%$ \\
\hline
\end{tabular}




\begin{tabular}{|l|l|l|}
\hline Viet nam & & $13.0 \%$ \\
\hline Yemen & & $15.9 \%$ \\
\hline Zambia & & $5.9 \%$ \\
\hline Zimbabwe & & $-1.2 \%$ \\
\hline & & \\
\hline
\end{tabular}

